\title{
Sobre espejos y espejismos en el auge de la bicicleta
}

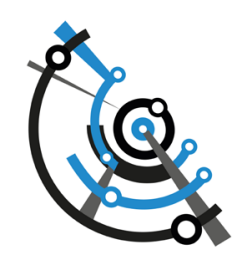

\section{Alfonso Sanz Alduán}

Grupo de Estudios y Alternativas 21 S.L., España.

\author{
Christian Kisters \\ Grupo de Estudios y Alternativas 21 S.L., España.
}

\author{
Marcos Montes \\ Grupo de Estudios y Alternativas 21 S.L., España.
}

Recibido: 19 de enero de 2018. Aceptado: 2 de mayo de 2018.

\section{Resumen}

El artículo hace un repaso de distintas estrategias de promoción de la bicicleta y, con ello, enmarca el debate entre las opciones de segregación de las infraestructuras ciclistas y la integración de la bicicleta en el tráfico motorizado. Analiza el perfil de las personas que utilizan la bici en los diferentes países que suelen servir de espejo de las políticas ciclistas, es decir, que se consideran referencias de éxito a seguir, y lo contrasta con el que existe en las ciudades latinoamericanas. Esa masiva presencia de bicicletas que tienen algunas ciudades y áreas metropolitanas puede ser un espejismo de la movilidad sustentable, pues en los ejemplos más conocidos sigue habiendo un uso dominante del automóvil. Esa paradoja sirve de llamada de atención sobre el riesgo de no contextualizar adecuadamente el papel de la bici en el seno de las políticas de movilidad sustentable.

Palabras clave

Movilidad Ciclista Tránsito Normalización de la bicicleta Transporte público

\section{Palavras chave}

Ciclista de mobilidade Tráfico

Normalização da bicicleta Transporte público

\section{On mirrors and mirages in the current boom of the bicycle}

\begin{abstract}
The article makes a review of different strategies of promotion of the bicycle. Its purpose is to frame the debate between the options of segregation of the cycling infrastructure and the integration of the bike on the motorized traffic. The text analyzes the profile of the people who use the bike in those countries that often serve as a mirror of the
\end{abstract}

Keywords 
policies cyclists, that is to say, that are considered references of success to follow, and it contrasts with the profile of users that exists in Latin American cities. This massive presence of bikes that have some cities and metropolitan areas can be an illusion of sustainable mobility, as in the best-known examples is still a dominant use of the automobile. That paradox serves as a warning sign about the risk of not contextualize the role of the bike within the sustainable mobility policies.

\section{espejo}

Del lat. speculum.

3. m. Modelo o dechado digno de estudio e imitación.

\section{espejismo \\ De espejo e -ismo.}

1. m. Ilusión óptica debida a la reflexión total de la luz cuando atraviesa capas de aire de densidad distinta, lo cual hace que los objetos lejanos den una imagen más cercana e invertida.

2. m. ilusión (concepto o imagen sin verdadera realidad).

\section{Diccionario de la Lengua Española}

Real Academia Española http://dle.rae.es

\section{Introducción}

En las dos últimas décadas la bicicleta ha vuelto a las ciudades de todo el mundo. En bastantes de ellas lo ha hecho sobre todo nominalmente en los discursos sociales y políticos, pero en otras muchas se ha hecho visible, ha retornado a las calles y a la acción de las instituciones.

Es llamativo a este respecto el enorme salto que han dado algunas organizaciones internacionales que hace no tanto tiempo ignoraban el potencial de la bicicleta en el transporte urbano, pero que ahora apoyan la acción local a favor de la movilidad ciclista ${ }^{1}$. No es baladí que en el $6^{\circ}$ Foro Mundial de la Bicicleta, celebrado en México en 2017, el Banco Iberoamericano de Desarrollo (BID) ${ }^{2}$ participara de un modo muy activo; ni que la Organización Mundial de la Salud recomiende políticas peatonales/ciclistas y la reducción del uso del automóvil (Oficina Europea de la OMS, 2016); ni tampoco que el programa de Naciones Unidas para el Medio Ambiente considere a la bicicleta una herramienta de la sostenibilidad y la lucha contra el cambio climático (PNUMA, 2016).

Se puede por tanto afirmar que el contexto es hoy mucho más favorable para hacer políticas profundas de movilidad ciclista que lo era hace un par de décadas. De hecho, desde China a Estados Unidos, de Méjico a Argentina, la bicicleta empieza a tener un cierto protagonismo en las políticas urbanas, favorecida por varios factores entre los que destacan:

» su idoneidad como alternativa,

» el coste político y económico limitado de algunas acciones y promesas para su desarrollo como medio de transporte,

» la existencia de voces que reclaman,

» las experiencias de éxito.

Precisar el alcance de esos factores permite también matizar el optimismo que se puede deducir del mencionado cambio de contexto que se percibe en todo el mundo. Es cierto que nos encontramos en otra fase, pero las dificultades para que la bicicleta encuentre su lugar en la movilidad urbana en la mayoría de las ciudades del mundo siguen siendo de una enorme envergadura.

1. Como señalaba Marcia D. Lowe en The Bicycle: Vehicle for a Small Planet, para el Worldwatch Institute (Worldwatch Paper no 90, septiembre de 1989), el informe del Banco Mundial titulado China Transport Sector Study (Washington, D.C., 1985) no mencionaba la palabra bicicleta en sus 400 páginas de extensión, a pesar de que en esos años todavía era el vehículo dominante de las ciudades chinas; en 1987 se vendieron en aquel país 35 millones de bicis, es decir, más que el número de automóviles vendidos en todo el mundo ese mismo año. A finales del siglo pasado, con la irrupción del concepto de transporte sustentable, la bicicleta empezó a ganar visibilidad, como pudo observarse en el documento estratégico del Banco Mundial titulado Sustainable Transport. Priorities for Policy Reforms (1996).

2. En los últimos años el BID ha publicado dos documentos que pretenden, precisamente, ayudar a la toma en consideración institucional de la bicicleta: Cómo impulsar el ciclismo urbano. Recomendaciones para las instituciones de América Latina y el Caribe (2017) y Ciclo-inclusión en América Latina y el Caribe: guía para impulsar el uso de la bicicleta (2015) 


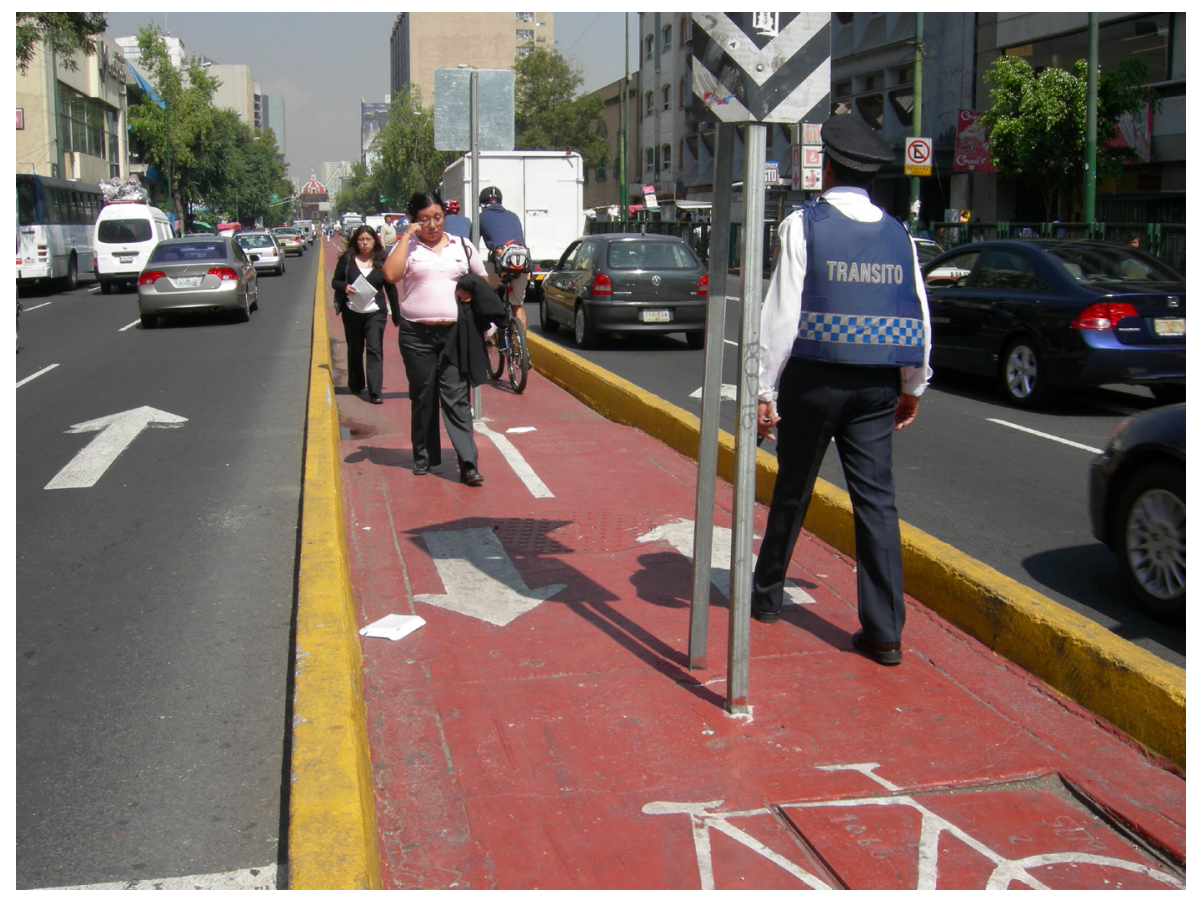

En efecto, los retos ambientales, económicos y sociales del mundo globalizado han cobrado virulencia y urgencia en estas dos primeras décadas del siglo XXI, con el cambio climático en primera línea de preocupación. Y la bicicleta se acopla como anillo al dedo a los discursos de esperanza, pues ofrece ventajas ambientales y de salud innegables, además de servir de medio de transporte barato y eficiente a quienes pueden y se atreven a utilizarla en ambientes muchas veces hostiles.

Pero que la bicicleta sea un vector positivo de gran utilidad para los desafíos del milenio no quiere decir, ni mucho menos, que sea una opción suficiente, por ejemplo, para doblegar las trayectorias climáticas o para modificar drásticamente los modelos de movilidad urbana hoy consolidados. La utilidad de la bicicleta como medio de transporte está limitada por un conjunto amplio de condicionantes entre los que se encuentra el propio modelo de ciudad y urbanización. Las grandes metrópolis del mundo han roto la escala de la bicicleta, están configuradas por relaciones de distancias que superan la ciclabilidad. Son espacios dependientes del motor y, en buena parte, destruidos o deshumanizados por las reglas impuestas por esa motorización. No basta cambiar algunos desplazamientos motorizados por desplazamientos ciclistas para construir una ciudad plenamente diferente y capaz de afrontar el cambio climático y el declive del petróleo.

El segundo factor mencionado, el limitado coste político y económico de algunas acciones y promesas que se están formulando respecto a la bicicleta es un arma de doble filo. Prometer algunos kilómetros de vías ciclistas y fotografiarse en marchas ciclistas es relativamente fácil, y así lo han hecho numerosos candidatos a puestos de responsabilidad política en estas dos décadas. Pero llevar a la práctica una transformación integral del espacio público y de la política de movilidad es algo mucho más difícil. De entrada, hay numerosos ejemplos de promesas ciclistas que se formulan al mismo tiempo que infraestructuras o programas que alimentan el uso del automóvil, sin reparar en la contradicción flagrante entre pensar la ciudad para el coche y pensar la ciudad para la bicicleta.

Se prometen así kilómetros de vías ciclistas y, al mismo tiempo, kilómetros de autopistas, comprobándose luego, en la mayoría de las ocasiones, que la inversión sigue centrándose en los vehículos motorizados y solo residualmente se dirige a los modos activos de desplazamiento.
Figura 1. La batalla por la calle en Ciudad de México. Fuente: A. Sanz. 


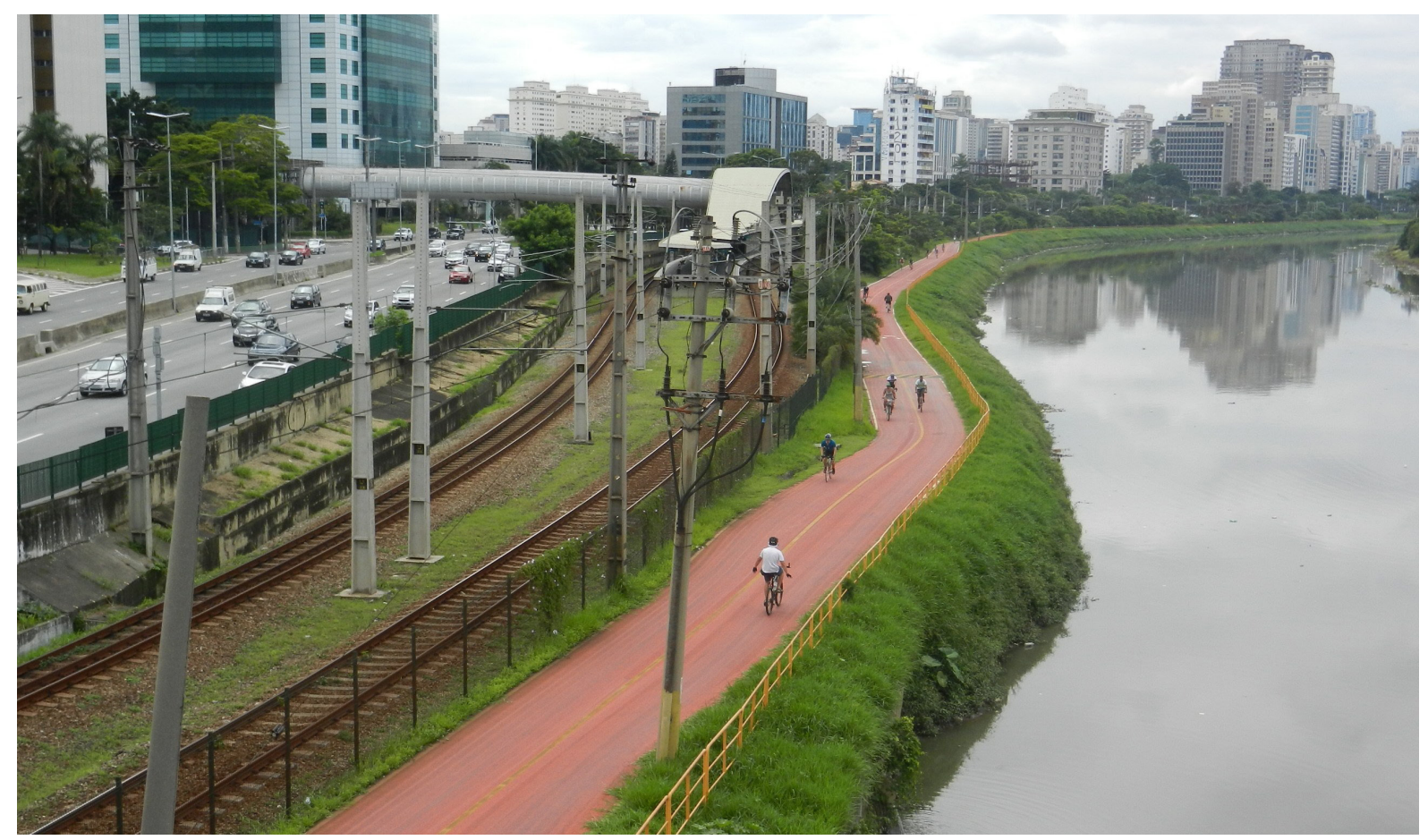

Es destacable también relacionar el auge con la presencia de grupos activos de defensa de la bicicleta. En todo el mundo han florecido organizaciones ciclistas con gran capacidad de intervención social y política, además de un considerable impacto en los medios de comunicación. Sin estas organizaciones no sería imaginable el cambio que se ha producido en los discursos sobre el modelo de movilidad. Ante la ausencia de organizaciones peatonales de potencia comparable ${ }^{3}$, el movimiento de defensa de la bicicleta, junto con el ecologismo, ha servido de punta de lanza social para revisar críticamente algunos de los conceptos y supuestos sobre los que se ha edificado en el último siglo la ciudad dependiente del automóvil. El alcance de este factor del auge de la bicicleta dependerá del rumbo que vayan tomando las propias reclamaciones pues, como luego se detallará, más bicicletas no se traducen necesariamente en movilidad más sustentable.

\section{La atracción del espejo y el riesgo del espejismo}

El último de los factores-impulso del auge de la bicicleta es el de contar con ejemplos reales sobre los que construir un imaginario colectivo pro-bici. Las ciudades, ricas o pobres, grandes o pequeñas, frías o cálidas, en las que la movilidad ciclista es masiva, deshacen tópicos y permiten situar el debate no en la posibilidad sino en el camino para llegar a la normalización del uso de la bicicleta. Las personas que viajan a estas ciudades son las mejores embajadoras de la causa ciclista, aunque tampoco es oro todo lo que reluce en ellas.

En efecto, las ciudades en las que la bicicleta está normalizada pueden servir de espejo, en esa acepción del diccionario que se refiere a modelo digno de estudio e imitación; son ciudades de las que se puede aprender de éxitos y también de fracasos siempre que se comprendan los aspectos que las diferencian de las que se quieren mirar en ellas pues, como se verá más adelante, muchas veces los cuellos de botella de la normalización tienen que ver más con el modelo urbanístico, el modo de vida o el sistema socioeconómico de cada lugar.
Figura 2. Y la guerra de las infraestructuras en São Paulo (Brasil). Fuente: A. Sanz.

3. La emergencia en las ciudades latinoamericanas de organizaciones peatonales es relevante sobre todo por su capacidad orientadora del discurso público sobre la mo-

vilidad. Ese es el caso de la Asociación de Peatones de Quito (https:// www.facebook.com/peatonesuio/), SampaPé de São Paulo (www. sampape.org) o la Liga Peatonal (http://ligapeatonal.org/) mexicana. 
La historia urbanística, cultural, social y económica de cada ciudad requiere aprovechar los espejos, con las cautelas imprescindibles. En el libro que relata las batallas por el espacio público en Nueva York durante su periodo como directora del área de transporte de la ciudad (2007-2013), siendo alcalde Michael Bloomberg (2002-2013), Janette Sadik-Khan dedica un capítulo al reconocimiento de ese aprovechamiento flexible de la experiencia ajena. Lo titula expresivamente como "Robando buenas ideas" (Stealing Good Ideas) y menciona que "Algunas de las mejores ideas para las calles de Nueva York fueron inspiradas, importadas, tomadas en préstamo, o lisa y llanamente, robadas de otras ciudades" (Sadik-Khan y Solomonow, 2016).

Las ciudades se inspiran unas a otras, pero necesariamente transitan su propio camino para alcanzar resultados positivos, nuevos y sorprendentes. Así ha ocurrido precisamente en el campo de la movilidad en las ciudades de Latinoamérica, en donde se ha sembrado el germen de al menos dos iniciativas de éxito mundial como son los metrobuses o las ciclovías dominicales.

En materia de política de la bicicleta, los espejos más celebrados son los de algunas ciudades y países europeos, como Holanda, Dinamarca, Bélgica o algunas regiones de Alemania e Italia. Sus cifras masivas de uso de la bicicleta son envidiadas por cualquier persona que quiere orientar su propia ciudad hacia la movilidad sustentable. Pero, lamentablemente, tampoco son el paraíso de la movilidad sustentable. En efecto, abriendo un poco el zoom del análisis, el panorama cambia sustancialmente. Así ocurre, en primer lugar, cuando se ponen en relación no solo el papel de la bicicleta, sino también el del automóvil, el del transporte público y el del peatón.

En las ciudades-espejo de la bicicleta todavía el uso del automóvil es muy elevado y no siempre la bicicleta es la mejor referencia de la sustentabilidad, tal y como se puede observar en la Figura 3.

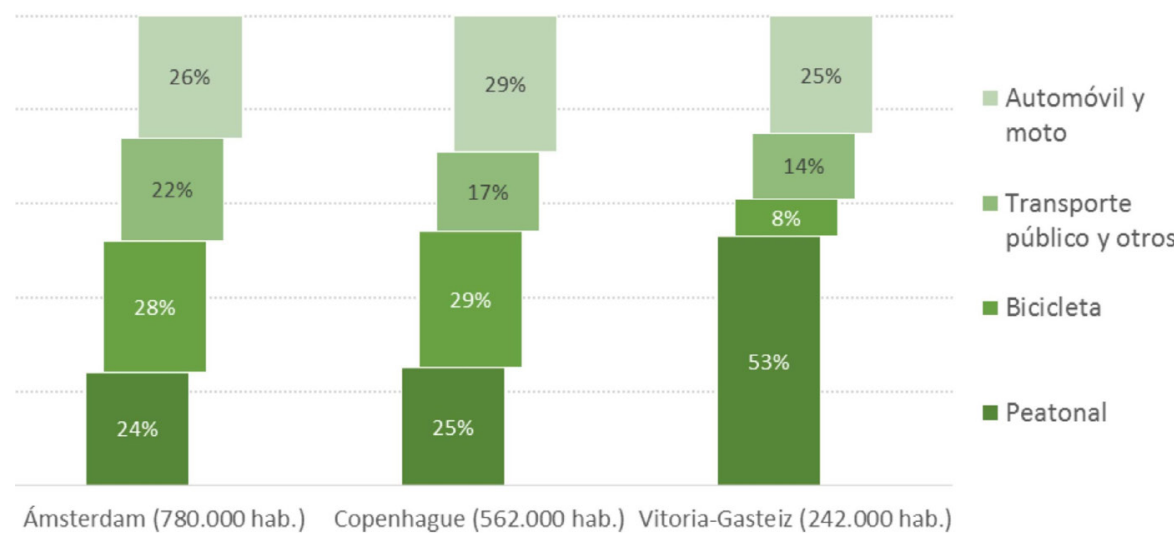

Es la suma de los medios de transporte activos (peatonal y ciclista) y colectivos lo que cualifica más claramente el modelo de movilidad. Por ese motivo, en la comparación con las ciudades de referencia, el papel de la bicicleta debe interpretarse también en esa clave, cuyo reverso es el peso del automóvil en el reparto modal.

Abrir el zoom, en segundo lugar, en cuanto a la dimensión espacial del análisis, también lleva a relativizar el esplendor de las ciudades de referencia. Cuando se dirige la mirada al área metropolitana, el panorama cambia drásticamente en las mismas ciudades mencionadas anteriormente.
Figura 3. Reparto modal de las ciudades de Ámsterdam, Copenhague y Vitoria-Gasteiz (España) en 2011. Fuentes: Elaboración propia a partir de datos de Ámsterdam y Copenhague procedentes de la publicación Cycling in the Oresund Region. A benchmark study (2010-2012)" (www. oresundsomcykelregion.nu) y de la CAPV procedentes del Estudio de la movilidad de la Comunidad Autónoma Vasca, 2011", publicado por el Departamento de Vivienda, Obras Públicas y Transportes del Gobierno Vasco (Vitoria-Gasteiz, 2012). 


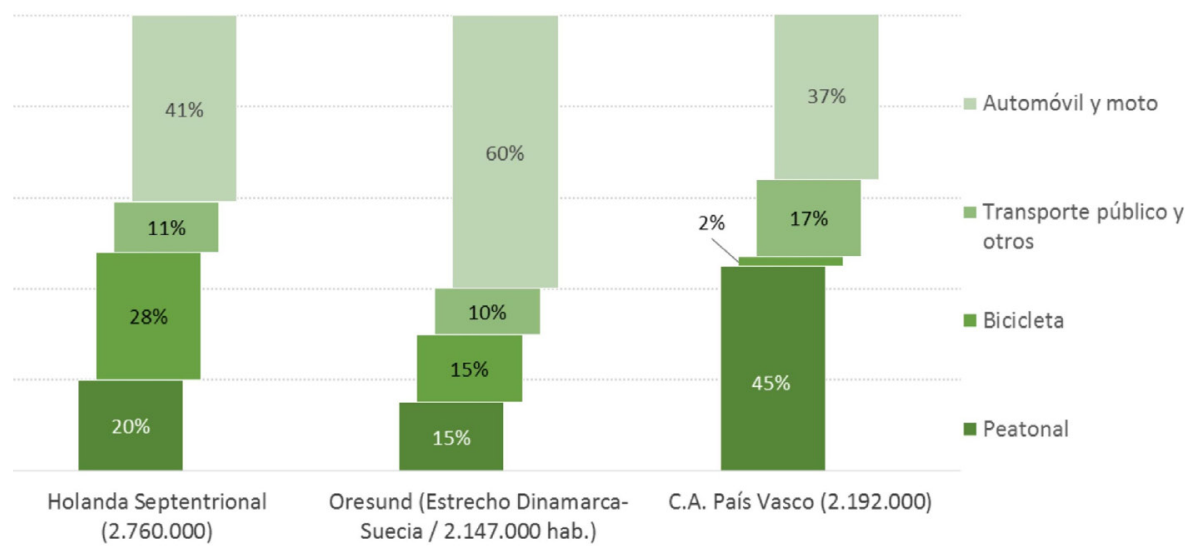

Esa ampliación de la mirada muestra las diferencias entre las ciudades principales y el resto del territorio, cuestionando la idoneidad en términos sustentables del modelo de movilidad vigente en esas regiones, que, por ejemplo, resulta incluso más dependiente del automóvil que la Comunidad Autónoma del País Vasco (España), en la que el uso de la bicicleta es relativamente reducido.

En definitiva, los ejemplos de ciudades ciclistas son de gran utilidad, pero requieren una interpretación más global, así como una adaptación local para armar una política de la bicicleta que se ajuste a las necesidades de cada lugar.

A veces los recursos más modestos pero cercanos pueden ser más valiosos, permitiendo eludir el riesgo del espejismo, es decir, el riesgo de caminar en una dirección equivocada por el deslumbramiento de los ejemplos canónicos.

Puede ocurrir que el oasis ciclista no esté donde lo imaginamos, ni nos permita ver el camino que está tomando la ciudad hacia modelos todavía más dependientes del automóvil. Porque lamentablemente, es frecuente encontrar ciudades que hacen planes de movilidad ciclista, promocionan la bicicleta y ejecutan infraestructuras ciclistas mientras despliegan políticas de mucho mayor calado que aumentan la dispersión urbana, generan atractivos para el uso del automóvil y hacen, en definitiva, más infernal el desierto del auto.

\section{Para quién la bicicleta}

Habitualmente se suele medir el auge de la bicicleta a través del número de ciclistas que utilizan este medio de transporte, su peso en el conjunto de desplazamientos (reparto modal) o la longitud de la red ciclista y el porcentaje de calles acondicionadas para su uso.

Si bien estos indicadores básicos son fundamentales para evaluar el avance y el éxito de las políticas de movilidad, es preciso encender otros focos para iluminar y entender mejor qué cambios han tenido lugar y cuáles faltan. Habrá que preguntarse cuáles son los perfiles de las personas que utilizan la bicicleta y cuáles son los motivos de sus desplazamientos. Si podemos dar respuestas a estas dos incógnitas, será más fácil diagnosticar si estamos ante un espejismo o si la bicicleta ha llegado para quedarse para siempre, contribuyendo al cambio del modelo de movilidad urbana.

Mirando el perfil de los usuarios de las ciudades y países que muchas veces nos sirven como espejo, es decir, los países con una cultura consolidada de la bicicleta, se observa que la bicicleta es un vehículo para todas las edades, todas las clases sociales y sin sesgo de sexo.
Figura 4. Reparto modal de las regiones a las que pertenecen las ciudades de Ámsterdam, Copenhague y Vitoria-Gasteiz (España) en 2011. Fuentes: Elaboración propia a partir de datos de Ámsterdam y Copenhague procedentes de la publicación Cycling in the Oresund Region. A benchmark study (20102012)" (www.oresundsomcykelregion. nu) y de la CAPV procedentes del Estudio de la movilidad de la Comunidad Autónoma Vasca, 201", publicado por el Departamento de Vivienda, Obras Públicas y Transportes del Gobierno Vasco (Vitoria-Gasteiz, 2012). 

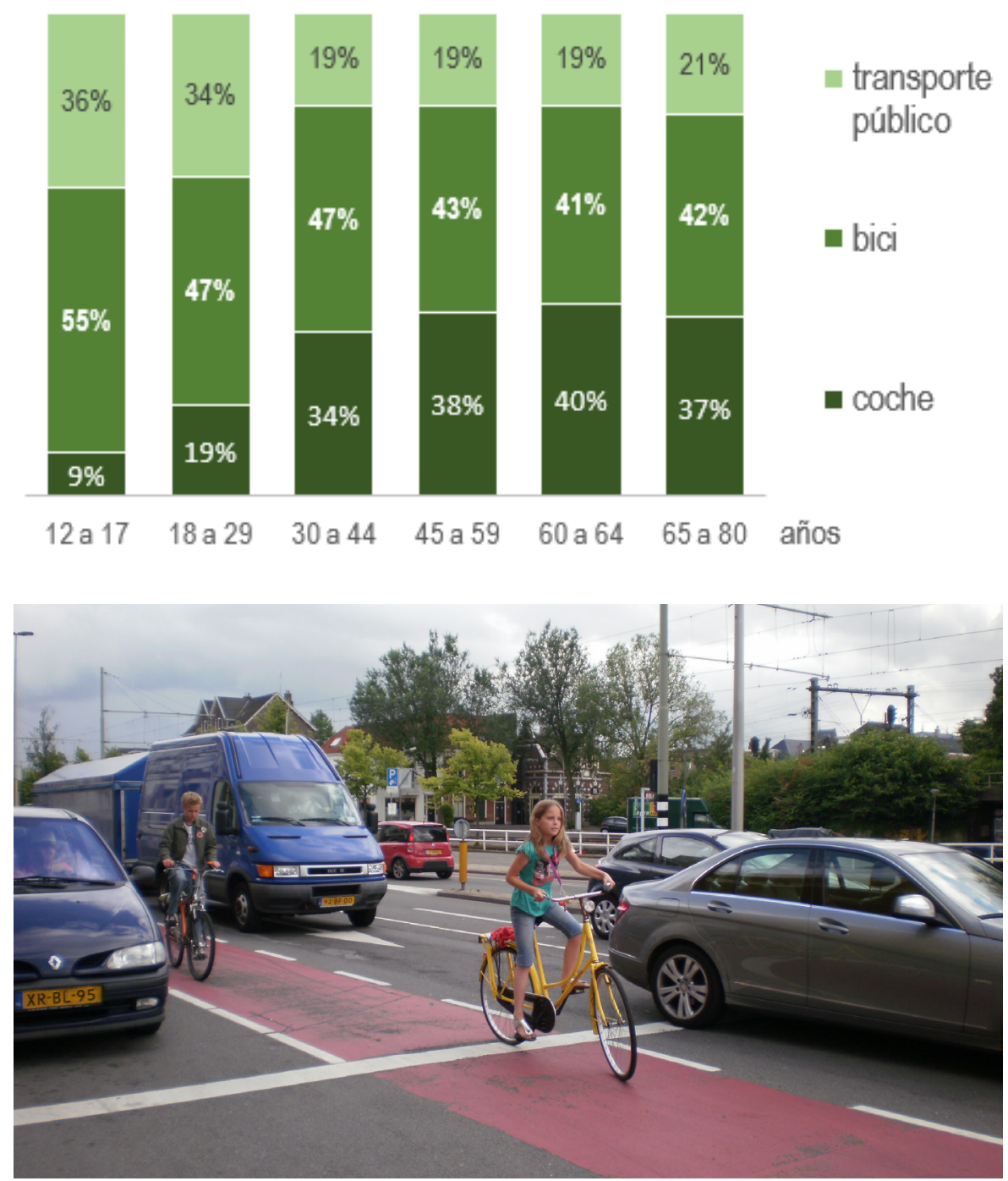

En el caso de la ciudad de Ámsterdam, con datos transferibles a otras ciudades con una cultura consolidada de la bicicleta, el mayor uso de la bicicleta se da entre los menores y se sigue manteniendo el hábito hasta edades avanzadas. Las cifras son relevadoras, ya que precisamente los grupos de usuarios que se suelen denominar como "vulnerables" -los menores y mayores- son los que más utilizan la bicicleta. En sociedades como la holandesa en las que la seguridad tiene un valor extraordinariamente elevado, la percepción del riesgo en la circulación ciclista debe ser muy baja para que haya un uso tan dominante de la bicicleta como modo de transporte. Así ocurre en Copenhague, otra ciudad de referencia, en la que solo un $6 \%$ de la población no se siente segura utilizando la bicicleta.

El otro indicador fundamental de la normalización del uso de la bicicleta es el reparto por sexos. En los países con una cultura ciclista consolidada las mujeres emplean la bicicleta en proporciones muy semejantes a los hombres.

La explicación del diferencial de uso de la bicicleta entre hombres y mujeres en ciudades en las que la bicicleta está poco consolidada no hay que buscarla en general en las exigencias físicas del pedaleo, sino en su respectiva sensibilidad en relación al riesgo.
Figura 5. Modo de transporte según grupos de edad en Ámsterdam. Fuente: Elaboración propia a partir de Amsterdamse Thermometer van de Bereikbaarheid, 2015 / https:// www.amsterdam.nl/parkerenverkeer/bereikbaar/thermometer/.
Figura 6. Menores en bicicleta en el tráfico de Delft (Holanda). Fuente: A. Sanz. 

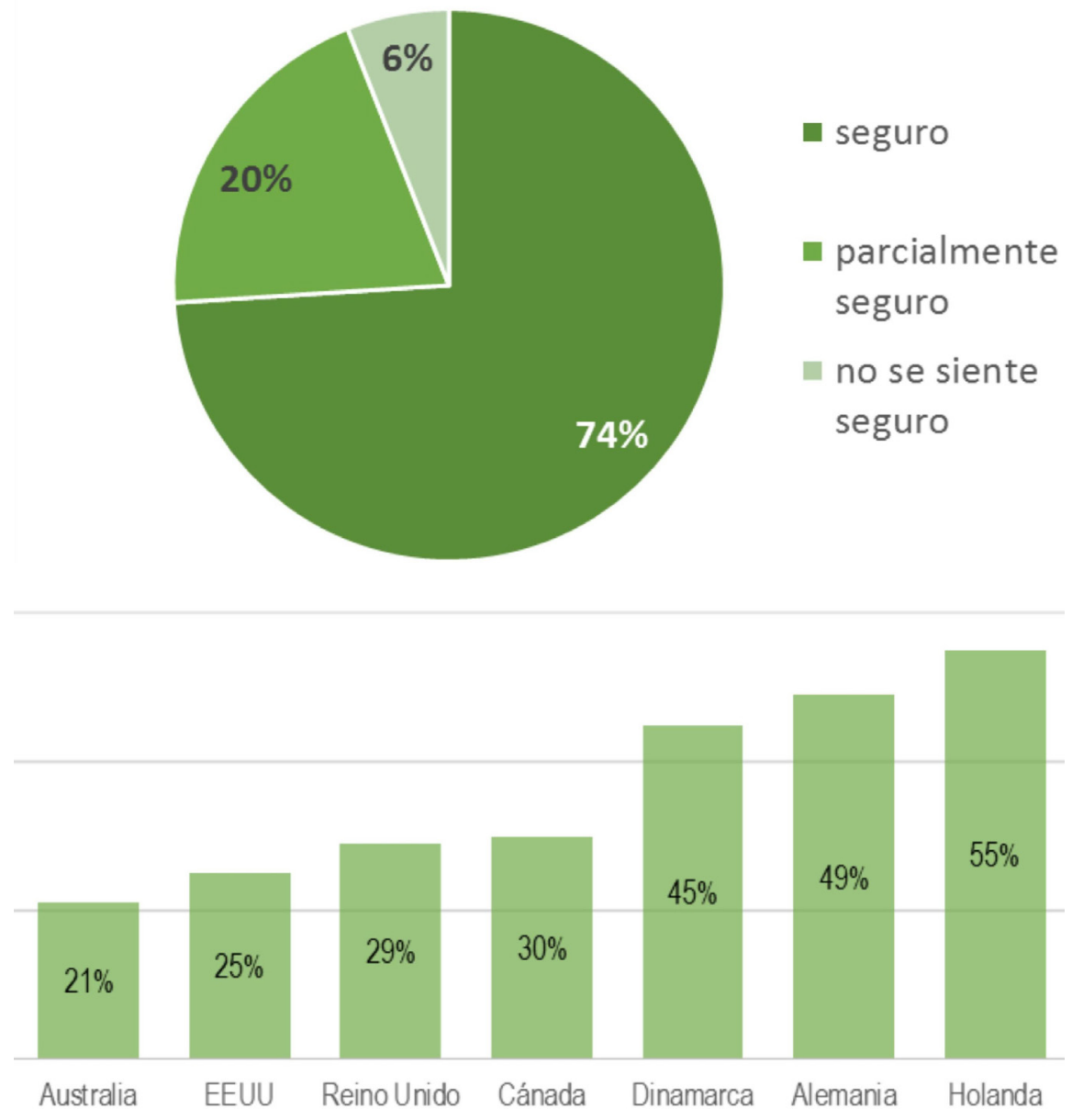

Los estudios sobre accidentabilidad de ciclistas, así como las encuestas sobre el riesgo percibido de los distintos grupos de usuarios ponen de manifiesto, que hay una diferencia considerable entre hombres y mujeres:

Hay evidencia de una correlación entre la conducta de seguridad vial, la propensión a tener accidentes y el sexo. Desde una edad temprana, los varones tienen más probabilidades que las mujeres de verse involucrados en accidentes de tránsito. Una de cada cuatro defunciones (el $73 \%$ ) por accidentes de tránsito afectan a hombres menores de 25 años, que tienen tres veces más probabilidades de morir en un accidente de tránsito que las mujeres jóvenes. ${ }^{4}$

La mayor exposición a situaciones de riesgo por parte de los varones, no está estrictamente relacionada con una diferente percepción del riesgo, sino más bien con una menor preocupación por parte de este grupo. Esta diferencia entre la percepción del riesgo y la preocupación explica en gran parte las diferencias en la frecuencia de los accidentes de tráfico en los dos grupos.

La mayor exposición a situaciones de riesgo por parte de los varones, especialmente en los grupos de edad más jóvenes, es también un hecho cuando se trata de peatones y ciclistas. Se ha comprobado que las mujeres que caminan son más sensibles a la seguridad vial que los hombres y suelen adoptar menos conductas de riesgo (Onieva y otros, 2016).
Figura 7. Porcentaje de habitantes de Copenhague que se sienten seguros utilizando la bicicleta. Fuente: Elaboración propia a partir de la publicación Copenhague, Ciudad de Ciclistas. El Conteo de la Bicicleta. Ayuntamiento de Copenhague 2014. Versión es español de la publicación en danés.

Figura 8. Proporción de mujeres entre las personas que utilizan la bicicleta en algunos países. Fuente: Elaboración propia a partir de Pucher, Buehler (2008).

4. Lesiones causadas por el tránsito. Centro de Prensa. WHO. Mayo 2017. http://www.who.int/ mediacentre/factsheets/fs358/es/ 


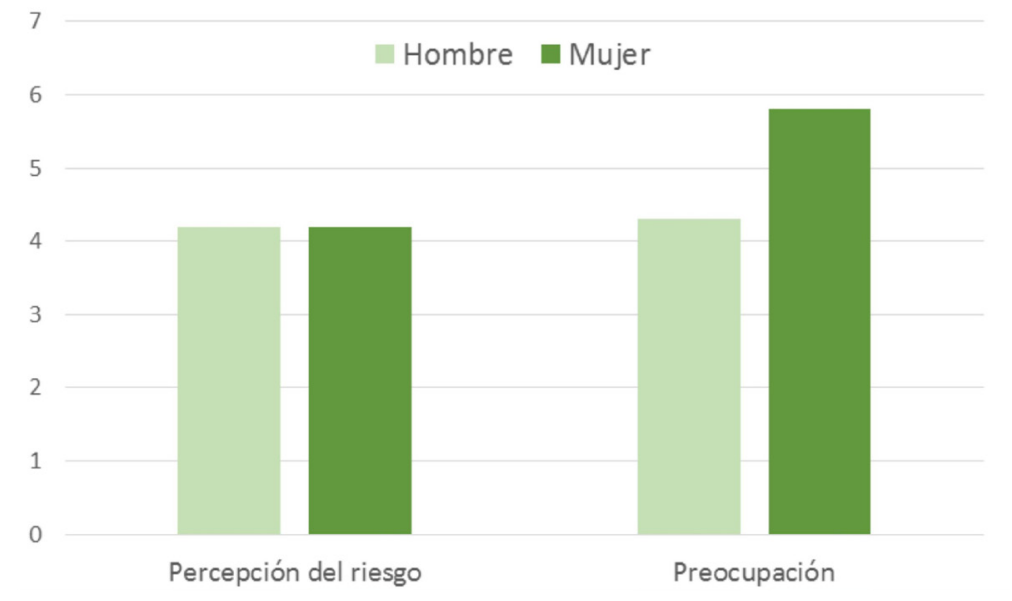

En resumen, los varones suelen estar dispuestos a correr más riesgos cuando eligen un modo de transporte, de manera que, en las ciudades que acaban de apostar por la bicicleta y que todavía no disponen de un clima favorable para su uso, los primeros grupos de usuarios suelen ser hombres, sobre todo con edades entre 25 y 40 años. Ese grupo percibe la circulación bajo las condiciones actuales "no óptimas" como más aceptable que el resto de usuarios potenciales.

\section{Inseguridad vial, estrés e inseguridad ciudadana}

Hay que advertir de que no todos los varones tienen esa disposición a correr riesgos; se trata más bien de una minoría como se puede desprender de un estudio reciente sobre la actitud de los habitantes de la ciudad de Portland (EEUU) hacia la bicicleta. Existe un porcentaje muy reducido de personas que usa la bicicleta en cualquier contexto $\mathrm{y}$ al que se puede denominar ciclistas "sin miedo" capaces de utilizar la bicicleta en condiciones desfavorables o entornos hostiles. Muchas veces, a parte de la "valentía", estos usuarios suelen tener una forma física superior a la media para desenvolverse con holgura en el tráfico.

Según este estudio, un 7\% de la población de Portland se puede incluir en la categoría de "ciclistas experimentados y confiados", que ya utilizan la bicicleta como modo de transporte o podrían si se mejorasen las condiciones (distancias más cortas de los viajes, mejor infraestructura para ciclistas, etc.). Este grupo se siente cómodo compartiendo la calzada con el tráfico motorizado, pero valoran positivamente la oferta de vías ciclistas segregadas.

Como ocurre en otras ciudades de todo el mundo, el grueso de la población de Portland está "interesada" en usar la bicicleta e incluso le gusta circular en este vehículo, pero está preocupada por la falta de condiciones mínimas de seguridad. Este grupo de personas se estresa cuando tiene que compartir la calzada si las velocidades o intensidades del tráfico motorizado son elevadas o, también, si los vehículos les adelantan dejando poca distancia. Conforma una amplia demanda latente sobre la que han de pivotar las políticas de movilidad ciclista.

Finalmente, un tercio de la población de Portland no está interesada en utilizar la bicicleta porque no le resulta práctico (por razones de la topografía, las distancias o la incapacidad de manejar una bicicleta).
Figura 9. Percepción del riesgo de accidente y preocupación según sexo. Fuente: Elaboración propia a partir de Cordellieri et al. (2016). 

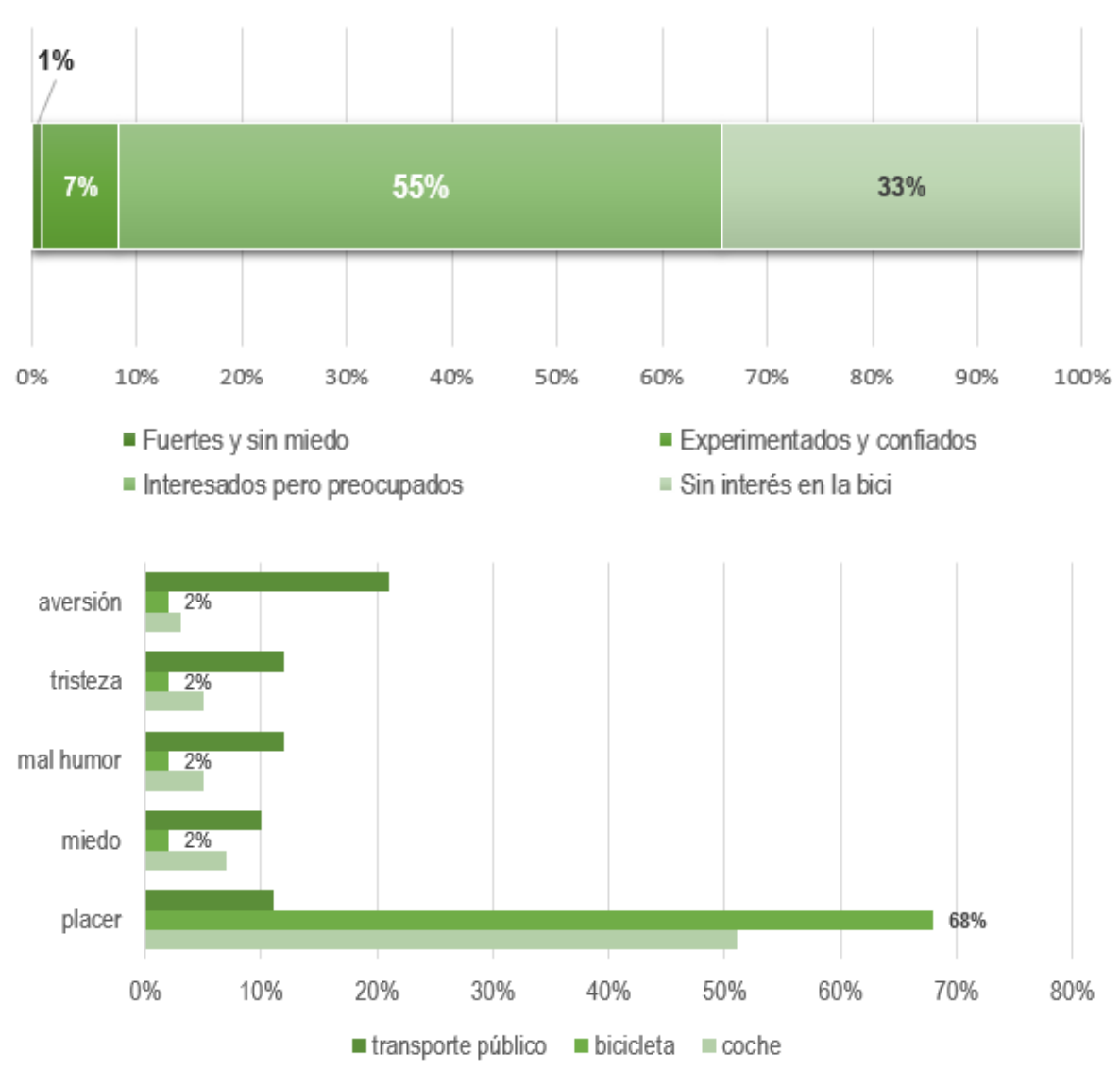

Esa categorización de la población de Portland según su actitud ante el uso de la bicicleta puede extrapolarse a otros muchos contextos urbanos y a la mayoría de las ciudades latinoamericanas, en donde las encuestas muestran similares preocupaciones, miedos $\mathrm{y}$ atracción hacia este medio de transporte.

La estrategia para captar la amplia franja potencial de personas que utilizarían la bicicleta en la ciudad empieza por tanto con el miedo, con la inseguridad. Montar en bici no debe requerir valentía. Nadie debe ser "valiente" para montar en bicicleta. Los ejemplos de Holanda, Dinamarca, Alemania, Suecia, Italia, etc. ponen de manifiesto que la bicicleta como modo de transporte es una opción viable no solo para una franja estrecha, sino para la amplia mayoría de su población, con independencia del sexo, de la edad o del estatus social.

Para complementar ese marco de la percepción de seguridad ciclista, algunos autores han introducido el concepto de ESTRÉS, es decir, la tensión que supone circular por una calle junto con vehículos de potencia y peso mucho más elevados. Aunque una calle sea segura en términos de velocidad de los vehículos y de accidentalidad puede seguir siendo un entorno que produzca agobio a la persona que pedalea por diferentes motivos (ruido, contaminación, congestión, etc.) que están estrechamente ligados a la cantidad de vehículos que circulan por una vía. Todos estos factores quedan resumidos en el concepto del "estrés".

Atendiendo a ese concepto se pueden clasificar los usuarios según su capacidad de aceptar la tensión producida por el tráfico motorizado. De ese modo, aparecen las mismas categorías señaladas más arriba: las personas fuertes y sin miedo, las experimentadas, las interesadas y los grupos vulnerables. En consecuencia, para atraer el máximo número de personas a la bicicleta, se debe reducir el estrés producido por el tráfico motorizado.
Figura 10. Grupos de usuarios de la bicicleta y distribución sobre la población de Portland. Fuente: Elaboración propia a partir de Geller (2007).
Figura 11. Emociones relacionadas con distintos modos de transporte en Holanda. Fuente: Elaboración propia a partir de la publicación Cycling in the Netherlands, CROW 2009. 
Figura 12. Factores adversos relacionados con el uso de la bicicleta. Fuente: Elaboración propia a partir de la publicación Bicycle Account Bogotá. Despacio 2014.

Y comprender, también, el otro significado del concepto de seguridad, la acepción vinculada a la criminalidad o la percepción de riesgo en el entorno social: la SEGURIDAD CIUDADANA. En Bogotá, el 56\% de la población afirma que el miedo a ser atacado es el principal factor adverso para ir en bici, incluso por delante del miedo de ser atropellado (el 53\%).

En la misma línea se manifiesta el informe "Biciciudades" del año 2013, según el cual "La barrera más grande que enfrentan los ciclistas en la región está relacionada a su seguridad vial y el miedo de ser asaltado" (BID, 2013).

Por razones obvias, la inseguridad ciudadana es un factor difícilmente abordable desde el ámbito sectorial de las políticas y la planificación de la movilidad, requiriendo un tratamiento mucho más amplio y profundo vinculado a las políticas urbanísticas, sociales y económicas.

\section{Sexo, edad y clase social en los perfiles de ciclistas en las ciudades latinoamericanas}

Como ocurre también en otros continentes, es difícil generalizar y cada país, incluso cada ciudad tiene sus singularidades. Aunque la información y los datos disponibles sobre el uso de la bicicleta y los grupos de usuarios es en general escasa y generalista, en la mayoría de los países y ciudades de este continente el papel de la bicicleta como modo de transporte es muy reducido y todavía no se ha introducido de forma consistente en la agenda social y política.

Según la guía "Ciclo-inclusión en América Latina y el Caribe" (BID, 2015), entre las grandes ciudades de esa región, son Rosario (Argentina) y Bogotá (Colombia) las que tienen una mayor proporción de viajes en bicicleta sobre el total, alcanzando aproximadamente el 5\%, mientras que en la mayoría de las demás ciudades de la región con cierta cultura ciclista esa cifra no supera el $3 \%$.

Hay también algunos casos de ciudades más pequeñas en las que la tradición ciclista, aun presionada por la motorización creciente, se ha mantenido en cotas elevadas. Este es el caso de Palmira (350.000 habitantes), que los medios de comunicación han calificado como la "Ámsterdam de Colombia", la cual registra un 15\% de los desplazamientos en bicicleta. Esa cifra muestra una reducción a la mitad del papel de la bicicleta en las dos últimas décadas, lo que suscita la duda sobre la evolución previsible a partir de ahora; la bicicleta ya está en la agenda social y política, pero quizás no con suficiente fuerza como para desviar el impacto de la motorización explosiva, del dominio del espacio público por las motos y los automóviles (Municipio de Palmira, 2013). 


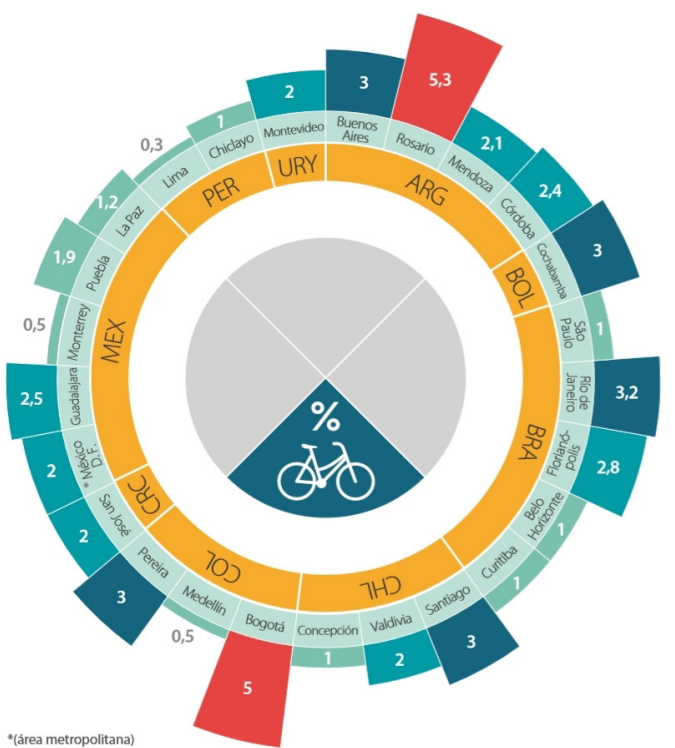

Mujeres $\mathbf{n}$ Hombres

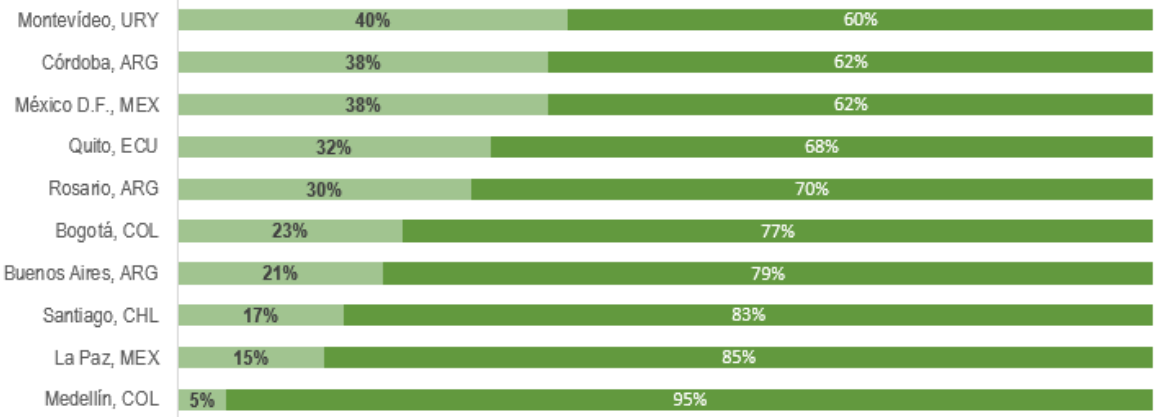

Más allá de las cifras generales, una mirada hacia los perfiles de personas que utilizan la bicicleta indica que su empleo como modo de transporte todavía no está consolidado pues, en primer lugar, hay un sesgo masculino, siendo la ciudad de Montevideo la más equitativa, con un $40 \%$ de mujeres entre quienes utilizan la bicicleta. En Bogotá, sin embargo, hay solo una mujer por cada cuatro varones ciclistas.

El caso de Buenos Aires muestra cómo el indicador de la participación de las mujeres en la movilidad ciclista ha evolucionado muy positivamente en el periodo $2009-2014$, triplicando el valor de base del 7\%. Desde entonces se mantiene estable alrededor del $20 \%$. Esta fase de crecimiento coincide con la ejecución de una red ciclista relativamente amplia, lo que sin lugar a dudas ha reducido la inseguridad percibida entre las mujeres.

El reto de Buenos Aires es, por tanto, aplicar políticas que vuelvan a dar un salto en la normalización de la bicicleta, haciendo más inclusivo su uso mediante la incorporación de una proporción más elevada de mujeres que aproxime esas cifras a las de otras ciudades latinoamericanas y a las de otros continentes con alto uso de la bicicleta.

Un segundo indicador importante de la normalización de la bicicleta es la presencia de ciclistas de todas las edades, comprobándose que, también en este aspecto, hay todavía un largo camino que recorrer en las ciudades latinoamericanas. En efecto, atendiendo por ejemplo al caso de la ciudad de Bogotá, la encuesta de movilidad de 2015 muestra que el uso de la bicicleta se corresponde sobre todo con personas adultas de entre $25 \mathrm{y}$ 45 años, mientras que los jóvenes y mayores tienen un peso inferior al que les corresponde demográficamente.
Figura 13. Uso de la bicicleta en las grandes ciudades latinoamericanas. Fuente: BID 2015.

Figura 14. Porcentaje de viajes realizados en bicicleta según sexo. Fuente: Elaboración propia a partir de Ríos et al. (2015) y de la ponencia Seguimiento de la demanda de ciclistas en CABA, Gerencia Operativa de Planeamiento Estratégico de la Movilidad, Ciudad Autónoma de Buenos Aires, 2017. 


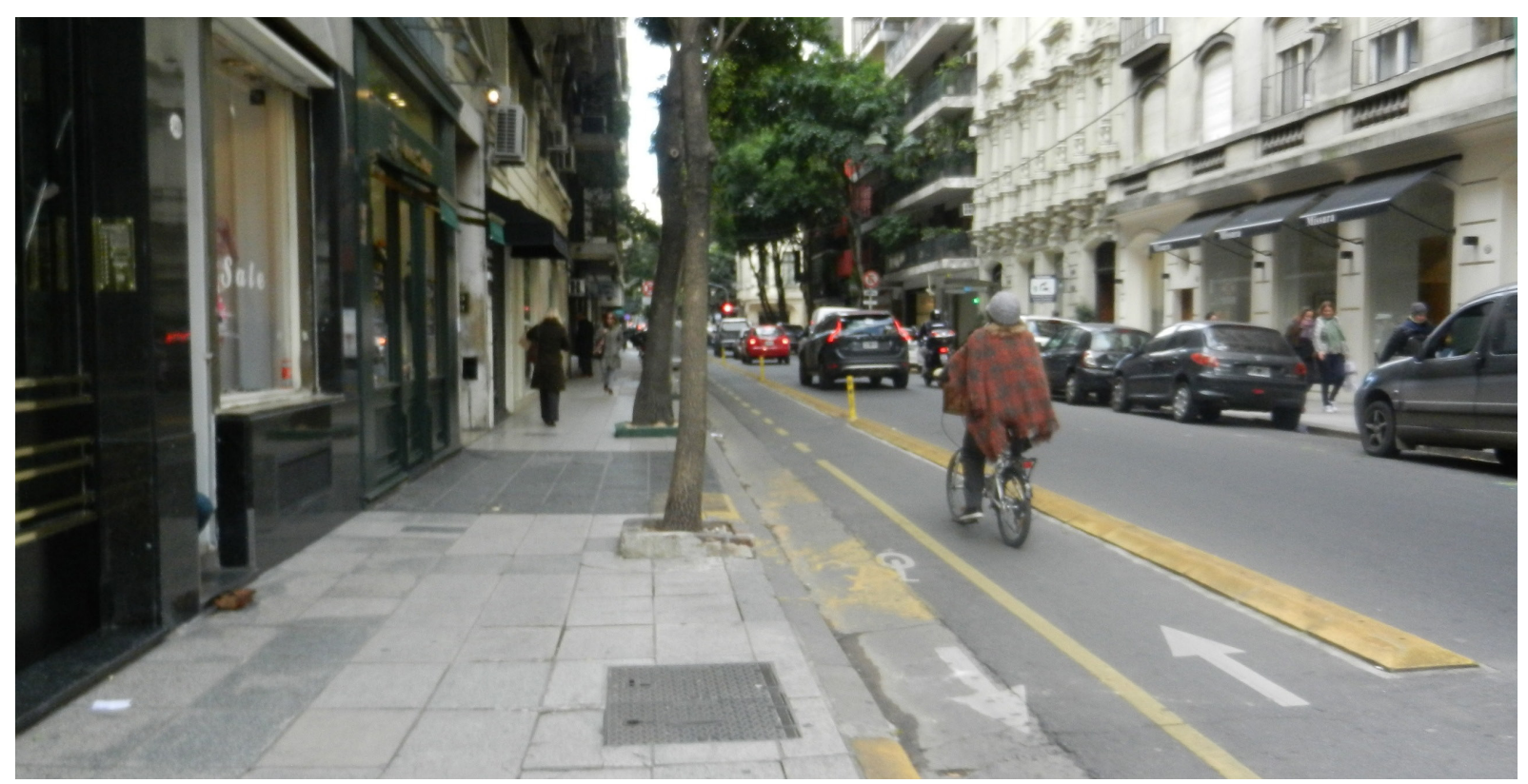

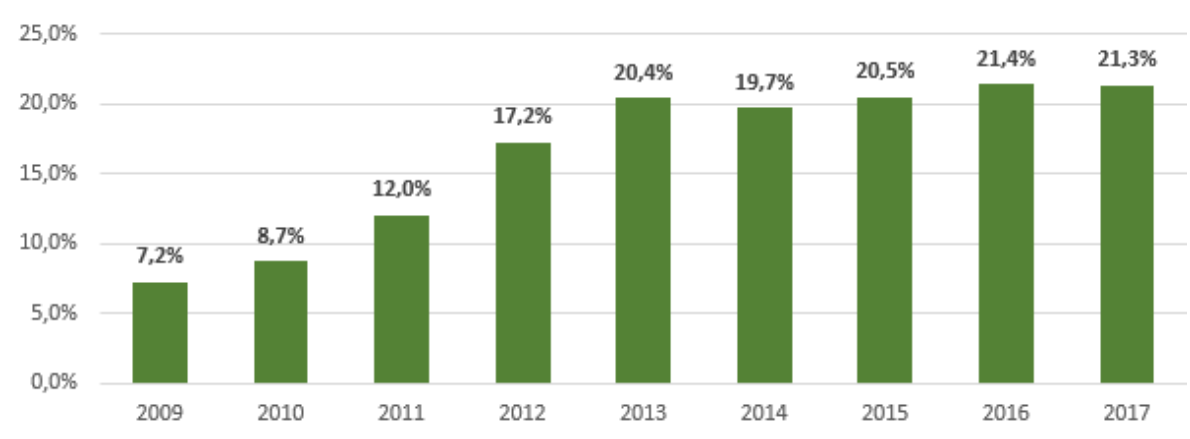

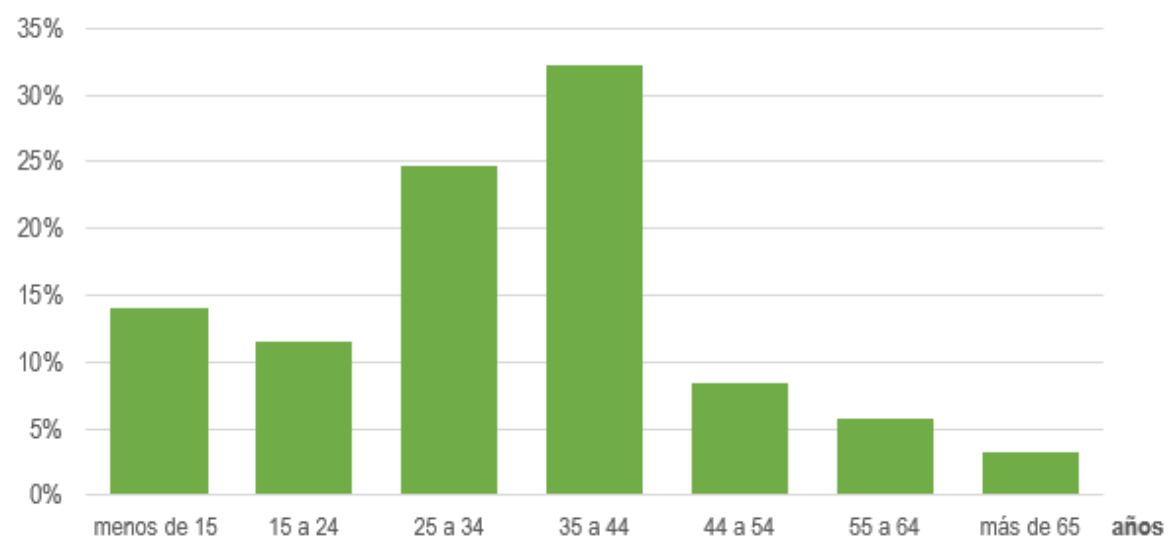

Figura 15. Mujer pedaleando en una vía ciclista de Buenos Aires. Fuente: A. Sanz.

Figura 16. Porcentaje de mujeres de los usuarios de la bicicleta en Buenos Aires. Fuente: Elaboración propia a partir del documento Seguimiento de la demanda de ciclistas en CABA, DG Planificación de la Movilidad, Buenos Aires Ciudad. Sin fecha.
Figura 17. Porcentaje de desplazamientos en bici según grupos de edad en Bogotá. Fuente: Elaboración propia a partir de Steer Davies and Gleave \& Centro Nacional de Consultoría (2011).

Un tercer y último indicador destacable de la normalización del uso de la bicicleta es su extensión entre los diferentes niveles de renta de la población. Como se ha indicado más arriba, la bicicleta es un vehículo para todas las clases sociales en los países europeos con una cultura ciclista consolidada, incluso puede encontrarse un mayor uso entre la población con mayor formación educativa. Sin embargo, esto no suele ocurrir en las ciudades latinoamericanas; en Bogotá, por ejemplo, desplazarse en bicicleta es más común entre las clases de rentas más bajas, aunque también se apunta una tendencia positiva en el estrato más elevado. 


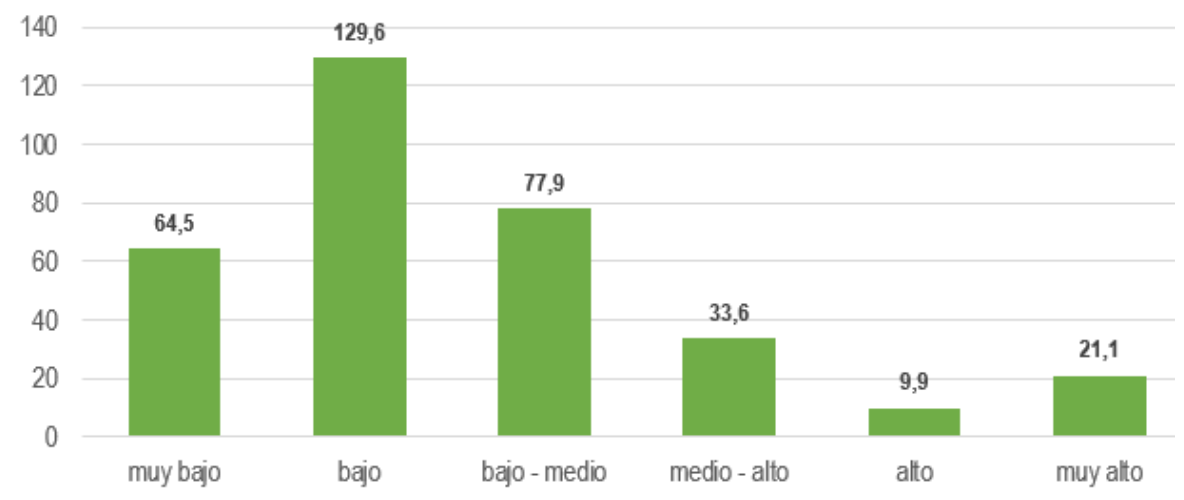

Figura 18. (Bogotá) Número de desplazamientos en bicicleta por cada 1.000 habitantes en cada estrato social en. Fuente: Bicycle Account Bogotá 2014. Despacio. 2015. El menor peso de la bicicleta en el estrato más bajo parece deberse en el caso de Bogotá a una localización que incrementa las distancias de desplazamiento hasta rangos no ciclables.

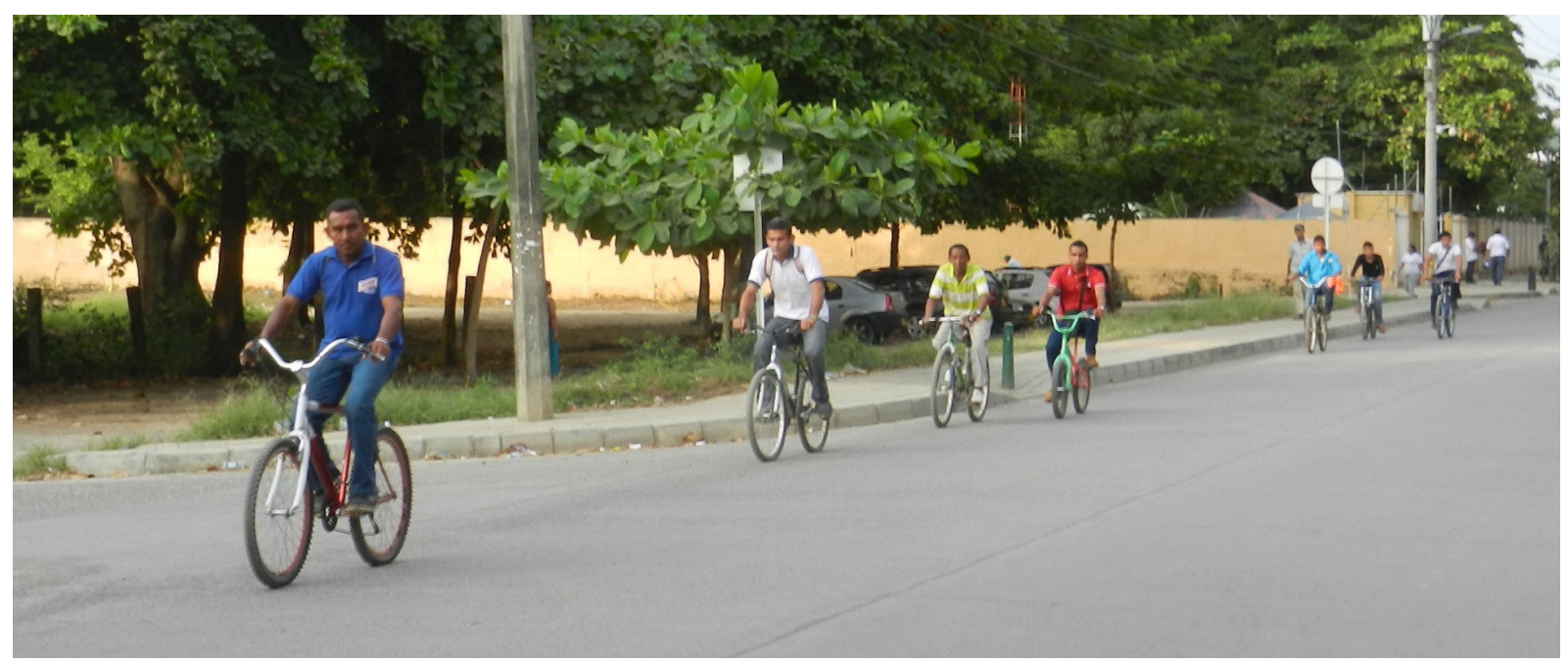

En otra ciudad colombiana de tamaño medio, Montería (450.000 habitantes en el municipio), con un $15 \%$ de desplazamientos en bicicleta en la partición modal, la mayor parte de las personas que utilizan la bicicleta (varones en un elevadísimo porcentaje) procede de barrios con renta baja, fundamentalmente de estratos 1 y 2 (Steer Davies and Gleave, 2012).

Se puede concluir así, como lo hace el informe "Biciciudades" (BID, 2013): "Mucha gente en América Latina y el Caribe aún ven a las bicicletas como un símbolo de clase socioeconómica baja. Sin embargo, hay estudios que indican un cambio en las percepciones de la bicicleta como una necesidad de la gente pobre hacia un signo de riqueza y cosmopolitismo".

En definitiva, la bicicleta en las ciudades latinoamericanas se enfrenta con una difícil normalización en la que no haya diferencias de uso por cuestión de sexo, edad o renta.
Figura 19. Trabajadores, mayoritariamente varones, como perfil principal de la movilidad ciclista en Montería (Colombia). Fuente: A. Sanz.

\section{Adversarios y aliados de la movilidad ciclista}

En cualquier caso, reducir el debate a la cuestión de la seguridad vial y del estrés, es dejar de lado otros aspectos clave de la movilidad ciclista, como la cultura, la psicología de la movilidad, el simbolismo del estatus y del poder en la jerarquía social, el sistema económico y fiscal o el marco institucional y regulatorio en el que se desenvuelve. 


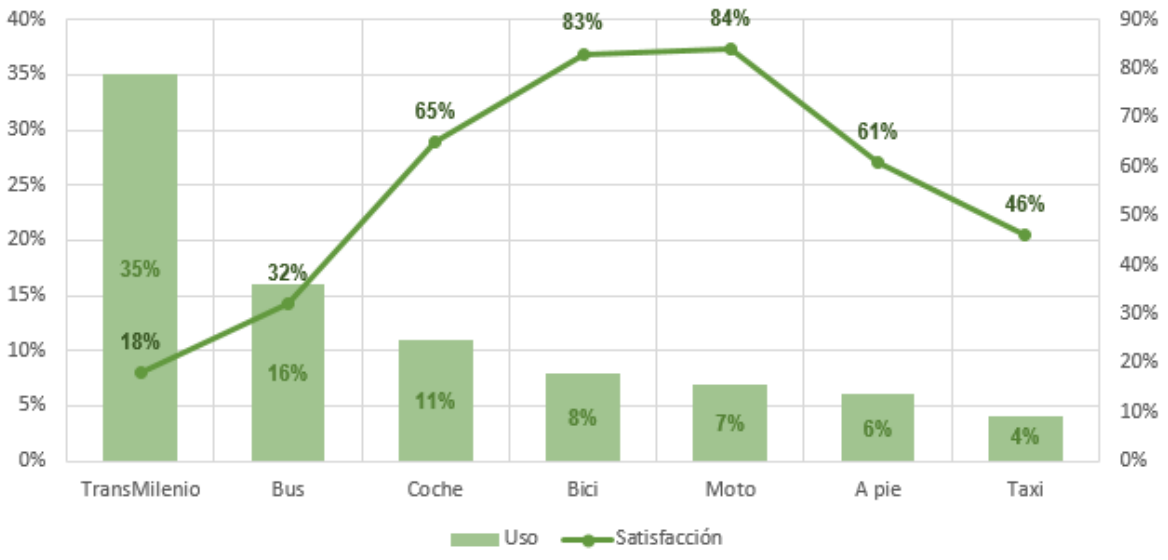

Sin atender todos esos otros factores no es posible alcanzar el éxito en las políticas de la bicicleta. Una red segura de infraestructuras ciclistas o un marco de circulación ciclista segura en la calzada será así una condición necesaria, pero no suficiente, para cambiar el modelo de movilidad y normalizar el uso de la bicicleta.

El urbanismo y la estructura territorial no solo condicionan la calidad del espacio público, a través de la distribución espacial de los usos, condicionan en gran medida las distancias entre la vivienda y los puestos de trabajo o los servicios; $y$, en consecuencia, contribuyen a generar mayores o menores necesidades de desplazamientos en modos motorizados al superar el radio de acción razonable de los modos activos.

Ya hace más de medio siglo, Jane Jacobs puso en evidencia en su libro "Muerte y vida de las grandes ciudades" (1961) que la ciudad multifuncional, compacta y densa, es la esencia de la cultura urbana, para la convivencia y para la seguridad. La calle, a diferencia de lo que planteaba el urbanismo moderno y lo que era el paradigma en la planificación de la movilidad del siglo pasado, no es un mero vacío para el tránsito de vehículos; la calle es una auténtica y compleja institución social donde desde la infancia se aprende a socializar y construir comunidad. Si la calle termina privilegiando al automóvil sobre el peatón y sobre la función estancial, la calle se muere y comienza el fin de la ciudad.

Así pues el uso masivo del automóvil en la ciudad es un condicionante clave de la calidad del espacio público y de la seguridad vial. Por lo tanto, el uso de la bicicleta solo será inclusivo y permanente si a la vez se reducen los impactos negativos del automóvil privado, cuestionándose el modelo de movilidad vigente, basado en la hegemonía de los modos motorizados.

Sin ese cambio de marco urbanístico y del modelo de movilidad, puede ocurrir, como muchas experiencias internacionales muestran, que el aumento del papel de la bicicleta se produzca en detrimento de otros modos sustentables, como por ejemplo el transporte público o los desplazamientos a pie, cuyas condiciones pueden estar valoradas más negativamente que la propia bicicleta. Este es el caso de la capital colombiana, tal y como se puede deducir de una encuesta de satisfacción, sintetizada en la Figura 20, según la cual las personas que utilizan la bicicleta están muy satisfechas con el modo de transporte, solo superadas por las que emplean el automóvil con chofer (aplicaciones tipo Cabify y Uber) y la moto.

Por consiguiente, si solo se opta por programas sectoriales pro-bici sin tener en cuenta las necesidades básicas del peatón (anchuras y adecuación de las aceras, continuidad de los itinerarios peatonales, espacio público de calidad, etc.) -que en muchos casos tampoco están resueltas-, es muy probable que el aumento del uso de la bici sea en primer lugar a costa de los desplazamientos a pie.
Figura 20. Satisfacción con los distintos modos de transporte de Bogotá. Fuente: Encuesta de percepción ciudadana Bogotá Cómo vamos 2016. 


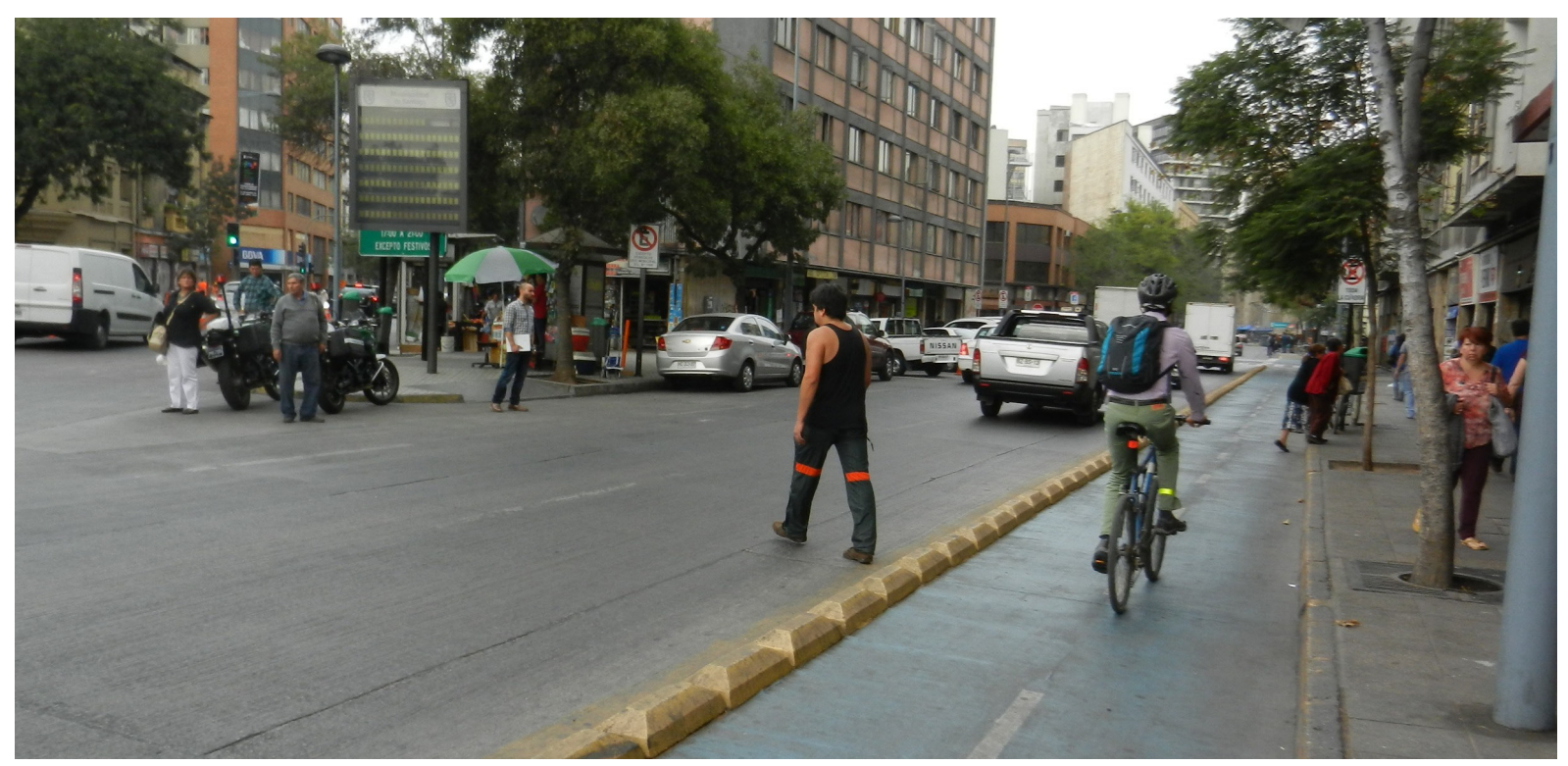

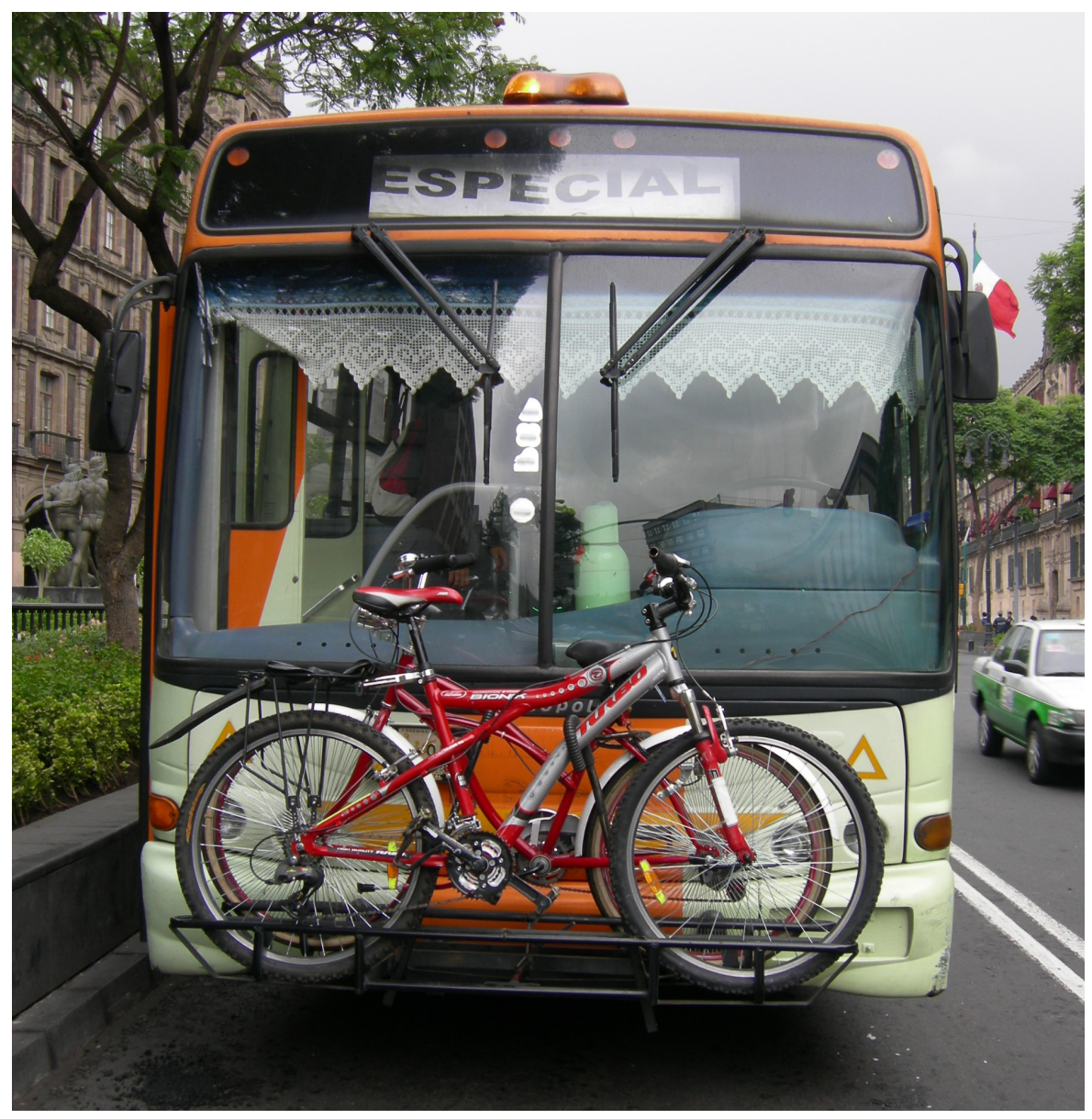

Una mirada hacia las ciudades más comprometidas tanto con la movilidad ciclista como con la movilidad sustentable en general sirve para darse cuenta que la bicicleta y el peatón son aliados y complementarios, cada modo tiene su rango de distancias idóneo. El peatón cubre perfectamente distancias de 1-1,5 km, es decir caminatas de 15-20 minutos, y la bicicleta entre 1 y $7 \mathrm{~km}$, que corresponden con desplazamientos de menos de 30 minutos. Se deduce así que la bicicleta no debería competir con el modo a pie, sino con los modos motorizados.
Figura 21. Vía ciclista que no se ha aprovechado para mejorar la permeabilidad peatonal en Santiago de Chile. Fuente: A. Sanz.

Figura 22. Intermodalidad en pruebas en Ciudad de México. Fuente: A. Sanz. 
Otro error frecuente cometido desde el enfoque sectorial de la bicicleta es implantar vías ciclistas a costa del espacio peatonal (para no poner en cuestión el estatus quo del automóvil) y/o optar por infraestructuras que generan fricciones con los peatones.

Desde un enfoque integral es importante recordar que la bicicleta es un vehículo y su espacio "natural" es la calzada. Este es un principio básico que debe regir la política de promoción de la movilidad ciclista en cualquier ciudad. La bicicleta, más allá de ser un modo de transporte, es una herramienta que contribuye, sin duda, a mejorar la habitabilidad de las ciudades, aunque sin olvidar que el protagonismo del espacio público le corresponde al peatón y más en general a las personas independientemente de si se desplazan o no.

Desgraciadamente hay muchos ejemplos donde las administraciones públicas han visto en las aceras un recurso fácil para ofrecer una alternativa "segura" a los ciclistas de forma inmediata, trasladando la presión del tráfico ciclista sobre el modo más vulnerable de la movilidad urbana, el desplazamiento a pie.

Los conflictos surgidos en los últimos años entre las bicicletas y los peatones son consecuencia de una serie de desajustes y enfoques en la planificación de la movilidad que han potenciado este conflicto en determinadas circunstancias o situaciones. Esos desajustes y enfoques se han traducido en el uso de los espacios peatonales por parte de los ciclistas, afectando a la comodidad y la seguridad del uso peatonal.

La relación con el transporte público de la bicicleta también es compleja, pues por un lado comparten potenciales usuarios en el rango de distancias inferior a $7 \mathrm{~km}$, pero por otro, pueden fortalecerse mutuamente. La bicicleta puede contribuir a ampliar el radio de acción del transporte público, y viceversa, si se facilita la Intermodalidad entre ambos modos de transporte. Así por ejemplo la cobertura de una estación de tren o autobús suele situarse en un radio de $500 \mathrm{~m}$, distancia, que se recorre a pie en 7,5 minutos, mientras que en ese tiempo la bicicleta puede desplazarse $1.500 \mathrm{~m}$, multiplicando por 9 veces la superficie cubierta andando.

\section{Integración vs segregación de la bicicleta en el tráfico, un debate mal enfocado}

En las ciudades emergentes en el uso de la bicicleta en América Latina la inseguridad vial es, junto con la inseguridad ciudadana, el principal factor disuasorio. Como medida para paliar este problema, la mayoría de la ciudadanía suele reclamar una mejor infraestructura para la bicicleta y programas de concienciación y respeto por parte de los conductores. Las vías ciclistas segregadas de la calzada se consideran un incentivo y un garante para utilizar la bicicleta en condiciones seguras.

En las ciudades en las que la bicicleta se ha normalizado sigue habiendo una parte de la opinión pública que reclama más vías ciclistas para mejorar la seguridad al pedalear, pero la mayor parte de las reclamaciones giran en torno a los comportamientos de los diferentes usuarios y en relación a la propia calidad de la infraestructura ciclista

En la mayoría de las ciudades no existe todavía una red ciclista suficientemente completa y de calidad, sino algunos tramos o itinerarios aislados, muchas veces en aquellas calles donde la implantación de una vía ciclista segregada era viable sin crear mucho rechazo entre determinados grupos de poder por la posible pérdida de aparcamiento de automóviles o por limitar la capacidad de una vía. 


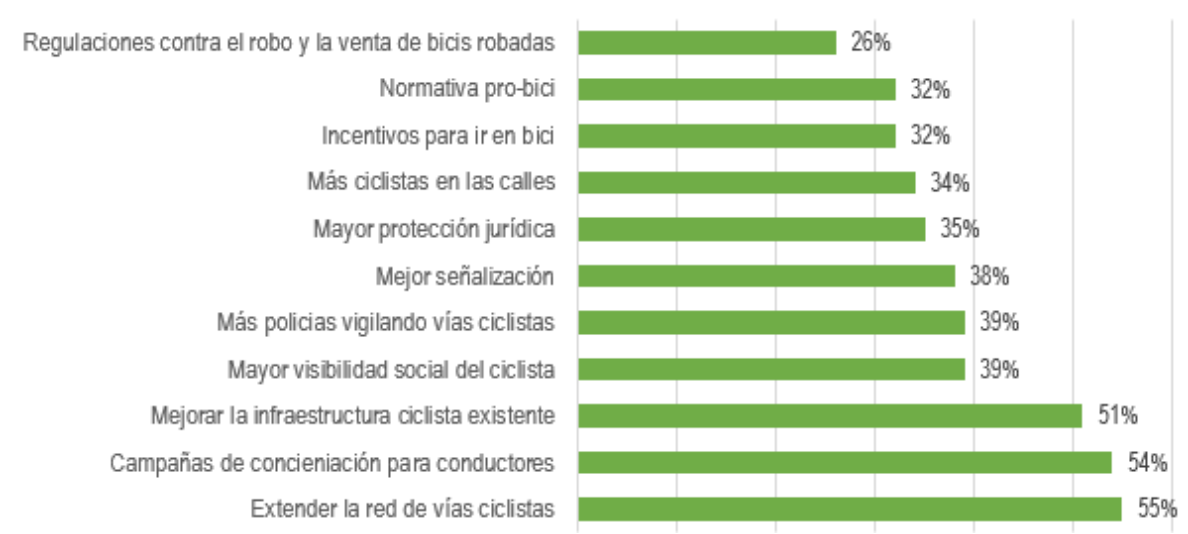

Vías ciclistas más anchas

Mayor respeto por parte de otros ciclistas

Más vías ciclistas

Mayor respeto por parte de los automovilistas

Más vías ciclistas alejadas del tráfico motorizado

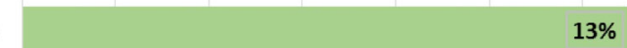

$10 \%$
$7 \%$

Además, las vías ciclistas ejecutadas están con frecuencia diseñadas aplicando conceptos y trazados erróneos, por múltiples razones que van desde la falta de conocimientos técnicos, a la falta de presupuestos o de voluntad política para la transformación profunda del espacio público, lo que abunda en que no se alcancen los objetivos esperados.

Ante el lento progreso hacia una red funcional de vías ciclistas y un diseño satisfactorio, hay grupos de activistas de la bicicleta que reclaman un enfoque diferente para su normalización que se resume bajo el concepto "ciclismo vehicular".

Este concepto fue acuñado por John Forester en la década de 1970 para caracterizar un estilo de ciclismo utilizado en su país natal, el Reino Unido, en contraste con el estilo deferente a los automóviles en Estados Unidos. En su libro "Effective Cycling", Forester sostiene que el ciclismo es más seguro cuando los ciclistas actúan y son tratados como conductores de vehículos.

Este enfoque presenta aspectos teóricos de gran interés, como la necesidad de contemplar las complejas dinámicas del comportamiento y la percepción del riesgo. En particular, recuerda la necesidad de introducir en los análisis de la seguridad vial los conceptos de "compensación del riesgo" y "riesgo homeostático", que se traducen en fenómenos paradójicos de incremento o decremento de la accidentalidad. Este es el caso, por ejemplo, del análisis de las intersecciones de las vías ciclistas segregadas, que han de ser tratadas considerando la necesidad de activar un grado superior de alerta en las personas que pedalean respecto al que tenían en el tramo separado del tráfico motorizado.

Sin embargo, la articulación práctica de ese enfoque es su mayor punto débil. No parece existir un camino para normalizar el uso de la bicicleta mediante la aplicación exclusiva del "ciclismo vehicular". Varias décadas más tarde, en las ciudades de EEUU en las que se ha promovido dicho enfoque como la mejor forma de potenciar el uso de la bicicleta, el ciclismo urbano sigue siendo marginal y el riesgo real y percibido es mayor que en los países con un uso consolidado de la bicicleta.

Figura 23. ¿Qué haría la bici un modo de transporte menos arriesgado en Bogotá?. Fuente: Elaboración propia a partir de Bicycle Account Bogotá. Despacio 2014.
Figura 24. Opinión sobre el modo de mejorar la seguridad ciclista en Copenhague. Fuente: Elaboración propia a partir de Copenhague, Ciudad de Ciclistas. El Conteo de la Bicicleta. Ayuntamiento de Copenhague 2014. Versión es español de la publicación en danés.
5. Véase al respecto, por ejemplo, el capítulo 4.8 del libro "La bicicleta en la ciudad". A. Sanz. Ministerio de Fomento (España). Segunda edición 1999, descargable en http://www.gea21.com/publicaciones/movilidad_ciclista) o, también, el capítulo 3.4 del libro "Calmar el tráfico. Pasos hacia una nueva cultura de la movilidad". A. Sanz. Ministerio de Fomento (España). 2008. (http://www.gea21.com/publicaciones/calmado_del_trafico). 


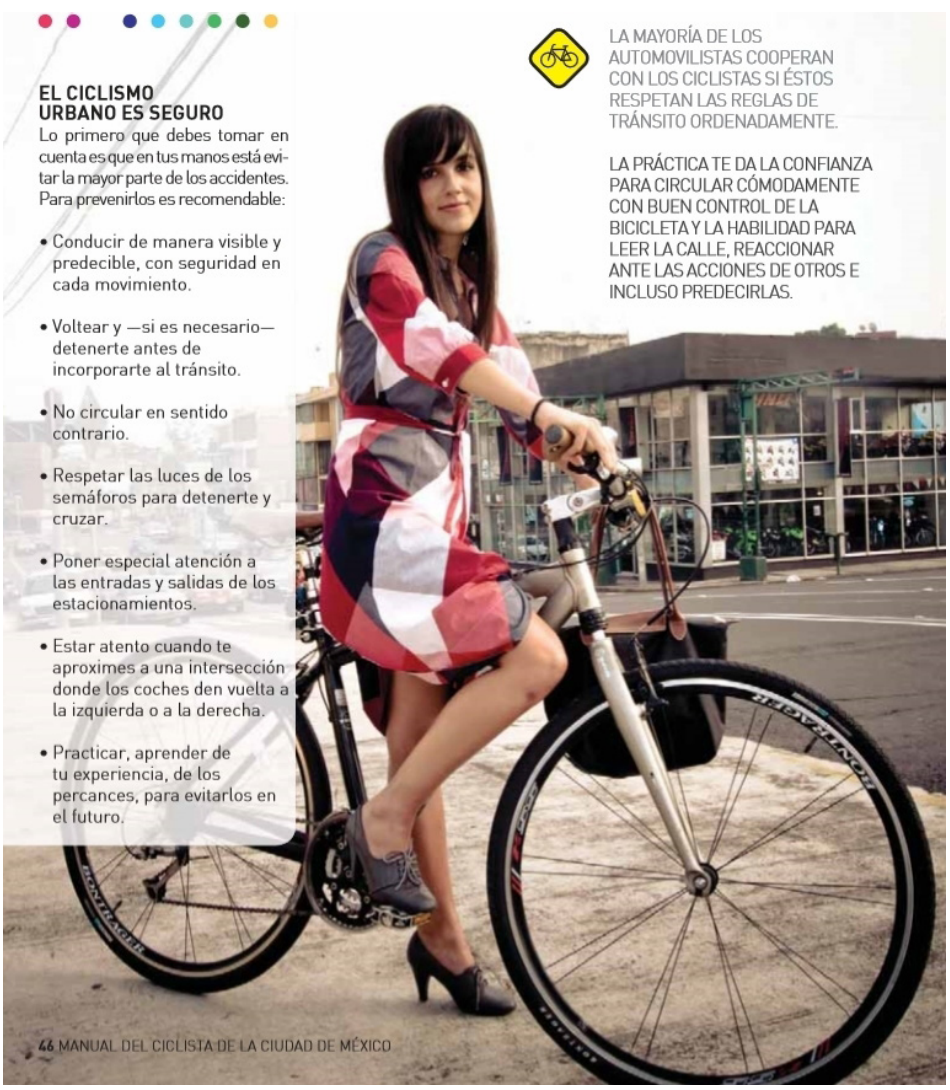

Por el contrario, ante la reciente evidencia de que la mejora de la infraestructura ciclista ha estimulado el uso de la bici en EEUU (Pucher y Buehler, 2016), muchos expertos afirman que la teoría del ciclismo vehicular ha perdido fuerza (Babin, 2016).

Uno de los principales errores del planteamiento vehicular típico ha sido intentar acoplar la circulación en bicicleta a las reglas impuestas por el tráfico motorizado (velocidad, prioridades, sentidos de circulación etc.), sin reconducir el modelo y la concepción de la movilidad en las ciudades. Solo unos pocos usuarios son capaces adaptarse al tráfico con garantías de seguridad -el grupo identificado como los "fuertes y sin miedo"- que, como bien es sabido, tiene un perfil tipo claramente definido: varón blanco entre 25 y 40 años.

Asimismo, parece un error pensar que es posible erradicar la inseguridad percibida mediante cursos de formación y de manejo de la bicicleta, así como a través de programas de concienciación. Ciertamente estas herramientas son necesarias y tienen su efecto, pero no transforman con suficiente profundidad la violencia vial estructural existente en las ciudades de todo el mundo.

En todo caso, la supuesta confrontación entre los enfoques de segregación $v s$ integración es algo superficial y artificial. En la mayoría de las ciudades con un uso de la bicicleta consolidado estos dos conceptos conviven en armonía, es decir hay calles donde la mayoría prefiere ir por vías ciclistas segregadas y calles donde la única opción es compartir la calzada.

Para las ciudades emergentes, lo que se requiere es una visión estratégica, en la que las medidas pro-bici pueden variar a lo largo del tiempo, adaptándose a los cambios en el propio proceso de normalización de la bicicleta (Pardo y Sanz, 2015).
Figura 25. Extracto del Manual del Ciclista Urbano de la Ciudad de México en el que se promueve el ciclismo vehicular. Fuente: Secretaría del Medio Ambiente del Distrito Federal, México 2011. 


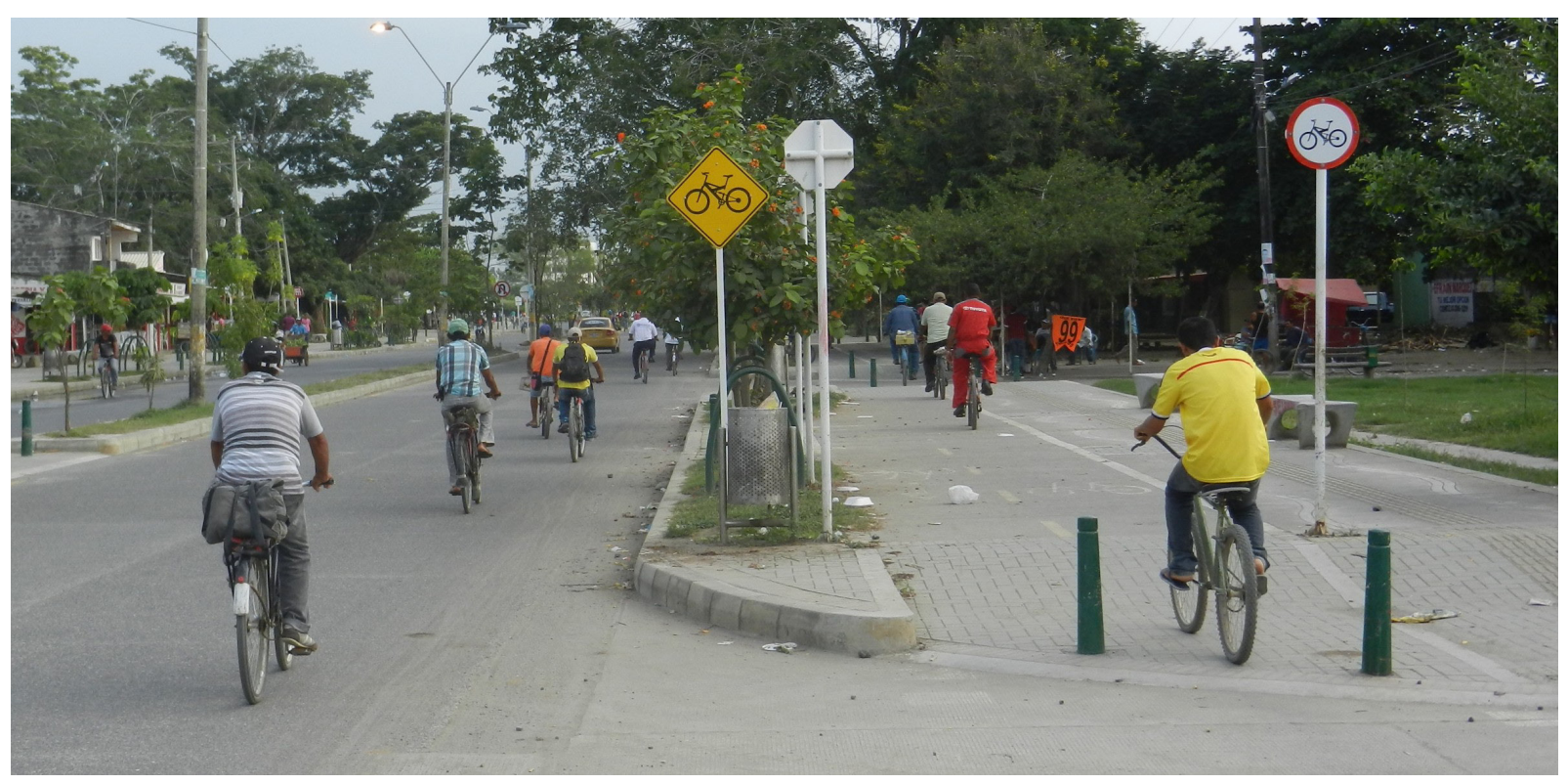

En una primera etapa de implantación de la movilidad ciclista (ciudades en fase de comienzo) el principal obstáculo para utilizar la bicicleta es el riesgo percibido para circular en calles donde los vehículos predominantes son los motorizados (automóviles, buses, furgonetas). En esos casos, la oferta de vías segregadas, combinada con medidas de calmado del tráfico en el viario local, aumenta notablemente la percepción de seguridad y, además, permite desplazarse de forma más tranquila, más relajada y sin afección de la congestión circulatoria.

Una vez consolidada la demanda, es mucho más fácil promover el uso compartido de la calzada, primero en calles con poco tráfico y velocidades bajas, ya que posiblemente habrá una masa crítica de ciclistas que se apropia parcialmente del espacio viario y visibiliza maneras diferentes de gestionar la convivencia entre vehículos.

Quizás el "ciclismo vehicular" sea un concepto apropiado para la teoría y a largo plazo, en un modelo idílico futuro de ciudad, pero su capacidad operativa como única solución en ciudades emergentes se antoja imposible.

En este sentido, la estrategia más eficaz y prometedora en lo que atañe a la infraestructura ciclista es la que combina las virtudes de la segregación e integración de la bicicleta en calzada:

》 integrar los distintos tráficos y hacer un uso compartido del viario, transformando los entornos urbanos locales mediante la aplicación de medidas de calmado del tráfico;

» segregar, mediante la creación de infraestructura específica y de uso exclusivo solo cuando los volúmenes de tráfico y las velocidades de circulación sean demasiado elevadas y puedan reducirse.

Así pues, los conceptos de la integración y la segregación no necesariamente son contrapuestos e incompatibles, sino más bien complementarios, ya que son de aplicación para lugares y personas diferentes. Todo suma: INTEGRACIÓN CUANDO Y PARA QUIEN SEA POSIBLE / SEGREGACIÓN DONDE Y PARA QUIEN SEA NECESARIO.

Incluso en una misma calle puede haber soluciones diferentes para satisfacer las necesidades de los distintos grupos de usuarios. Puede haber perfectamente una vía ciclista
Figura 26. La demanda desborda el uso de la infraestructura ciclista en Montería (Colombia). Fuente: A. Sanz. 
segregada y simultáneamente un carril señalizado como "ciclocarril" para avisar de la posible presencia de ciclistas en la calzada en la misma calle. Es lo que hemos denominado SISTEMA DUAL, en la planificación reciente de la movilidad ciclista en Madrid (Gea 21 SL, 2016).

En definitiva, una estrategia capaz de integrar cuando se puede y segregar cuando se debe es la más opción más prometedora ya que garantiza unas condiciones básicas adecuadas, tanto en términos de seguridad como de atractivo (es decir un "nivel de estrés" bajo) asumible para la amplia mayoría de la población - la demanda latente -. Una estrategia que se extiende a todo el viario, incluyendo tanto las calles principales como las locales, las calles en polígonos industriales como las calles residenciales, las calles en los centros urbanos como las vías periurbanas e interurbanas de las áreas metropolitanas.

\section{Conclusión}

El auge de la bicicleta, su aceptación institucional y su inclusión en las agendas sociales y políticas en la mayoría de las ciudades del mundo, puede considerarse una oportunidad excelente para modificar los modelos de movilidad hacia patrones más sustentables; hacia modelos capaces de afrontar el reto del cambio climático y el declive del petróleo.

Para ello es preciso desplegar una ESTRATEGIA integral de la bicicleta, una suerte de hoja de ruta de la política de movilidad ciclista que establezca y programe las principales líneas de actuación en esta materia, en el marco de un cambio de rumbo general en la política de movilidad y urbanística general.

Con ese fin, cada ciudad debe ponerse ante el espejo, mirar con atención sus rasgos y proponerse objetivos propios para normalizar la bicicleta como medio de transporte cotidiano. En ese proceso de reflexión es útil conocer la experiencia de otras ciudades, tener otros modelos a imitar y adaptar, pero sin caer en el espejismo de las soluciones fáciles y sin costes.

Porque, efectivamente, la normalización de la bicicleta requiere transformaciones mucho más profundas de lo que pudiera pensarse. Sobre todo requiere un nuevo imaginario colectivo que rompa los viejos espejos y disuelva los espejismos que fascinan todavía mucho más que los de la bicicleta. Por ejemplo, el espejo de las ciudades norteamericanas, apoyadas en la generalización del uso del automóvil, la extensión de la individualización de la vida privada y la dispersión de la urbanización.

O el espejismo de las soluciones tecnológicas de repuesto del automóvil actual; ese deslumbramiento por la electrificación y la automatización de la conducción del automóvil, que promete resolver todos los problemas de este vehículo sin renunciar a su uso masivo, sin modificar la manera de conformar nuestro modo de vida y nuestras ciudades.

No es posible soñar al mismo tiempo la ciudad de las bicicletas y la ciudad de los automóviles eléctricos y autónomos. Un espejo rompe el otro. 


\section{Q Bibliografía}

»Amsterdamse Thermometer Van de Bereikbaarheid (2015). <https://www. amsterdam.nl/parkeren-verkeer/bereikbaar/thermometer/>.

»Avellaneda, P., Lazo, A. (2011). Aproximación a la movilidad cotidiana en la periferia pobre de dos ciudades latinoamericanas. Los casos de Lima y Santiago de Chile. Revista Transporte y Territorio 4.

» Banco Interamericano de Desarrollo (2013). Biciudades: un estudio regional acerca del uso de la bicicleta como medio de transporte en América Latina y el Caribe. Washington.

» Banco Interamericano de Desarrollo (2015). Ciclo-inclusión en América Latina y el Caribe. Publicación redactada por RÍOS FLORES, Ramiro Alberto; TADDIA, Alejandro; PARDO, Carlosfelipe; y LLERAS, Natalia.

» Bogota Cómo Vamos (2017). ¿Cómo vamos con la bicicleta? Informe basado en la encuesta de percepción ciudadana del año 2016.

»Ciudad Autónoma de Buenos Aires (2017). Seguimiento de la demanda de ciclistas en CABA. Ponencia de la Gerencia Operativa de Planeamiento Estratégico de la Movilidad.

»Copenhague (2014). Ciudad de Ciclistas, El Conteo de la Bicicleta. Ayuntamiento de Copenhague 2014.

" Cordellieri, P., Baralla, F., Ferlazzo, F., Sgalla, R., Piccardi, L., Giannini, A. M. (2016). Gender Effects in Young Road Users on Road Safety Attitudes, Behaviors and Risk Perception. Front Psychol., 7: 1412.

" CROW (2009). Cycling in the Netherlands.

»Despacio (2014). Bicycle Account, Bogotá.

" GEA 21, SL (2016). Plan Director de Movilidad Ciclista de Madrid. Revisión y Actualización. Ayuntamiento de Madrid.

» Geller, R. (2006). Four Types of Cyclists. Portland Bureau of Transportation, Portland, Ore., 2006.

»Martínez-Ruiz, V., Jiménez-Mejías, E., Amezcua-Prieto, C., Olmedo-Requena, R., Luna-del-Castillo, J., Lardelli-Claret, P. (2015). Contribution of exposure, risk of crash and fatality to explain age- and sex-related differences in traffic-related cyclist mortality rates. Accidental Analisis and Prevention. Marzo 2015.

» Municipio de Palmira (2013). Formulación y adopción del Plan de Movilidad para el Municipio de Palmira.

» Observatorio de Movilidad Urbana (2016). Informe 2015-2016, resumen ejecutivo. CAF, Banco de Desarrollo de América Latina, 2016.

» Oficina Europea de la OMS (2016). Physical activity strategy (2016-2025). Copenhague, 2016.

»Onieva, M.-A., Martínez, V., Lardelli, P., José Juan Jiménez, J.-J., Amezcua, C., Luna-Del-Castillo, J., Jiménez, E. (2016). Gender and age differences in components of traffic-related pedestrian death rates: exposure, risk of crash and fatality rate. Injuried Epidemiol., 3 (1): 14. 
»Pardo, C., Sanz Alduán, A. (2015). Guía de ciclo-infraestructura para ciudades colombianas. Ministerio de Transportes de Colombia. Disponible en <http:// www.gea21.com/publicaciones/movilidad_ciclista>.

»Perez Salaverria, T., (2011). Inseguridad de las mujeres en los espacios públicos de las ciudades de América Latina. Tesis Fin de Master, Universidad de Complutense de Madrid, 2011.

»Pnuma (2016). Global Outlook on Walking and Cycling. Policies \& realities from around the world. 2016.

»Pucher, J., Buehler, R. (2016). Safer Cycling Through Improved Infrastructure. Am J Public Health, 106 (12): 2089-2091.

»Pucher, J., Buehler, R. (2008). Making Cycling Irresistible: Lessons from The Netherlands, Denmark and Germany. Transport Reviews 28.

»Real Academia Española (2017). Diccionario de la Lengua Española. Página web http://dle.rae.es. 2017 es la última fecha de actualización. Fecha de consulta: 10 de enero de 2018.

»Red de Ciudades por la Bicicleta (2015). Barómetro de la bicicleta en España, GESOP.

»Sadik-Khan, J., Solomonow, S. (2016). Street fight. Handbook for an urban revolution. Viking. New York, 2016.

»Sanz Alduán, A., Pérez Senderos, R., Fernández, T. (1999). La bicicleta en la ciudad. Ministerio de Fomento. Madrid, Segunda edición 1999, (descargable en http://www.gea21.com/publicaciones/movilidad_ciclista).

"Sanz Alduán, A. (2008). Calmar el tráfico. Pasos hacia una nueva cultura de la movilidad. Ministerio de Fomento. Madrid, http://www.gea21.com/ publicaciones/calmado_del_trafico.

»Sanz Alduán, A. (2018). Bicicletas y autoridades locales. Guía de políticas de movilidad ciclista para municipios de Gipuzkoa, Navarra y Pirineos Atlánticos. Diputación Foral de Gipuzkoa, http://www.geaz1.com/publicaciones/ bicicleta_y_gobiernos_locales

»Secretaría del Medio Ambiente del Distrito Federal (2011). Manual del ciclista urbano de la Ciudad de México, México.

»Steer Davies and Gleave, \& Centro Nacional de Consultoría (2011). Informe de indicadores. Encuesta de Movilidad de Bogotá, 2011. Bogotá.

»Steer Davies and Gleave (2012). Formulación del Plan de Movilidad del Municipio de Montería. Informe preparado para el Departamento Nacional de Planeación. Marzo de 2012.

\section{Sitios internet}

» Marqués, Ricardo, blog: Londres: ciclismo en transición sábado, 5 de agosto de 2017, $<$ http://movilidad-activa.blogspot.com.es/>.

》 Mikael Colville-Andersen, blog: Vehicular Cyclists - Cycling's Secret Sect: <http:// www.copenhagenize.com/2010/07/vehicular-cyclists-secret-sect.html>.

" Babin, T. blog: Vehicular cycling is dead, just don't bury the body yet, Shifter / Blog, $2016<$ http://shifter.info/vehicular-cycling-is-dead-just-dont-bury-the-body-yet/>. 


\section{Alfonso Sanz Alduán / asanz@geaz1.com}

Geógrafo, matemático y Técnico Urbanista. Ha trabajado como consultor en una treintena de ciudades españolas y latinoamericanas, colaborando en su planificación urbanística y de la movilidad. Entre sus publicaciones destacan: "La bicicleta en la ciudad" (Ministerio de Fomento, segunda edición 1999), "Calmar el tráfico. Pasos hacia una nueva cultura de la movilidad" (Ministerio de Fomento, 2008), "Guía de ciclo-infraestructuras para las ciudades colombianas" (Ministerio de Transportes de Colombia, 2016), "Cuentas Ecológicas del Transporte en España” (2016) y "Caminar en la Ciudad. Manual de movilidad peatonal” (Editorial Garceta, 2016).

\section{Christian Kisters / ckisters@geaz1.com}

Ingeniero en Planificación Territorial de la Universidad de Dortmund (Alemania). Es especialista en la redacción de Planes de Movilidad Urbana Sostenible, con el foco de atención en los modos no motorizados. Ha participado en la redacción de numerosos trabajos relacionados con la movilidad ciclista en diferentes niveles de la administración pública en España y Latinoamérica. Ha colaborado como docente en diversos cursos de postgrado y dictado ponencias en seminarios y congresos sobre movilidad sostenible.

\section{Marcos Montes García / mmontes@geaz1.com}

Arquitecto con una dilatada experiencia profesional en planificación y diseño del espacio público. Ha colaborado en la redacción de numerosos planes de movilidad sostenible, como el Plan Director de Movilidad Ciclista de Madrid (2008) y su revisión en 2016 o el Plan Director de Movilidad Alternativa de Galicia (2011). Además, llevó a cabo la asistencia técnica para la creación de una red de ciclovías en el área metropolitana de Managua (PNUD-GEF; 2014). Entre sus publicaciones recientes destaca "Denontzako Kaleak. Guía para actuaciones de mejora peatonal y ciclista novedosas y/o de coste reducido" (IHOBE, Gobierno Vasco, 2016). 